\title{
Induction of Activity-Dependent LTD Requires Muscarinic Receptor Activation in Medial Prefrontal Cortex
}

\author{
Douglas A. Caruana, E. Clea Warburton, and Zafar I. Bashir \\ MRC Centre for Synaptic Plasticity, School of Physiology and Pharmacology, University of Bristol, Bristol BS8 1TD, United Kingdom
}

\begin{abstract}
The medial prefrontal cortex (mPFC) forms part of a neural circuit involved in the formation of lasting associations between objects and places. Cholinergic inputs from the basal forebrain innervate the MPFC and may modulate synaptic processes required for the formation of object-in-place memories. To investigate whether acetylcholine regulates synaptic function in the rat mPFC, whole-cell voltage-clamp recordings were made from pyramidal neurons in layer V. Bath application of the cholinergic agonist carbachol caused a potent and long-term depression (LTD) of synaptic responses that was blocked by the muscarinic receptor antagonist scopolamine and was mimicked, in part, by the $\mathrm{M}_{1}$ receptor agonists McN-A-343 or AF102B. Furthermore, inhibition of PKC blocked carbachol-mediated LTD. We next determined the requirements for activity-dependent LTD in the prefrontal cortex. Synaptic stimulation that was subthreshold for producing LTD did, however, result in LTD when acetylcholine levels were enhanced by inhibition of acetylcholinesterase or when delivered in the presence of the $\mathrm{M}_{1}$-selective positive allosteric modulator BQCA. Increasing the levels of synaptic stimulation resulted in $\mathrm{M}_{1}$ receptor-dependent LTD without the need for pharmacological manipulation of acetylcholine levels. These results show that synaptic stimulation of muscarinic receptors alone can be critical for plastic changes in excitatory synaptic transmission in the mPFC. In turn, these muscarinic mediated events may be important in the formation of object-in-place memories. A loss of basal forebrain cholinergic neurons is a classic hallmark of Alzheimer's dementia and our results provide a potential explanation for the loss of memory associated with the disease.
\end{abstract}

\section{Introduction}

Acetylcholine is important for different forms of learning, memory, and experience-dependent plasticity. Lesions of cholinergic nuclei (Aigner et al., 1991; Everitt and Robbins, 1997), disruption of cholinergic transmission (Ebert and Kirch, 1998), or genetic deletion of acetylcholine receptors (Anagnostaras et al., 2003) impairs cognitive function, although the reasons for the deficits remain controversial. We have shown that object recognition memory and long-term depression (LTD) in perirhinal cortex rely on activation of muscarinic acetylcholine receptors (mAChRs) (Massey et al., 2001; Warburton et al., 2003), suggesting that muscarinic-mediated synaptic plasticity may be important for recognition memory. Object-in-place memory is a form of associative memory that depends critically on perirhinal cortex and medial prefrontal cortex (mPFC) (Kesner and Ragozzino, 2003; Browning et al., 2005; Barker et al., 2007; Barker and Warburton, 2009). The mPFC is innervated by several neuromodulatory systems, including inputs from the nucleus basalis, and blockade of

Received Sept. 15, 2011; revised Nov. 2, 2011; accepted Nov. 2, 2011.

Author contributions: E.C.W. and Z.I.B. designed research; D.A.C. performed research; D.A.C. analyzed data; D.A.C. and Z.I.B. wrote the paper.

This research was funded by grants to Z.I.B and E.C.W. from the Biotechnology and Biological Sciences Research Council.

Correspondence should be addressed to Zafar I. Bashir, MRC Centre for Synaptic Plasticity, School of Physiology and Pharmacology, University of Bristol, Bristol BS8 1TD, UK. E-mail: z.i.bashir@bristol.ac.uk.

D.A. Caruana's present address: National Institute of Environmental Health Sciences, National Institutes of Health, Research Triangle Park, NC 27709.

DOI:10.1523/JNEUROSCI.4719-11.2011

Copyright $\odot 2011$ the authors $\quad 0270-6474 / 11 / 3118464-15 \$ 15.00 / 0$
mAChRs in mPFC impairs object-in-place memory (Barker and Warburton, 2009). However, the mechanisms by which mAChRs regulate object-in-place memory in $\mathrm{MPFC}$ are unknown.

There are five $m A C h R$ subtypes $\left(M_{1}\right.$ to $\left.M_{5}\right)$ that couple to numerous intracellular cascades and membrane channels (Levey, 1996; Eglen, 2006). Pharmacological activation of mAChRs facilitates induction of long-term potentiation (LTP) in various brain regions (Blitzer et al., 1990; Burgard and Sarvey, 1990; Bröcher et al., 1992; Patil et al., 1998) and, under some circumstances, produces a lasting enhancement of synaptic transmission in hippocampus (Ito et al., 1988; Auerbach and Segal, 1994, 1996; Kojima and Onodera, 1998). Blockade of acetylcholine receptors can also block induction of LTP (Hirotsu et al., 1989; Katsuki et al., 1992; Kobayashi et al., 1997; Hess and Donoghue, 1999). Furthermore, mAChR activation facilitates (Kirkwood et al., 1999) or induces LTD in visual cortex (McCoy and McMahon, 2007) and induces LTD in perirhinal cortex (Massey et al., 2001). Activation of mAChRs can either increase (Markram and Segal, 1990; Harvey et al., 1993; Buchanan et al., 2010) or decrease (Jo et al., 2010) NMDA-mediated transmission, and this modulation of NMDARs may explain, at least in part, how mAChRs can affect synaptic plasticity.

Despite the known role of acetylcholine in mPFC-dependent learning and memory (Dunnett et al., 1990; Broersen et al., 1995; Ragozzino and Kesner, 1998; Dalley et al., 2004; Ross et al., 2005; Barker and Warburton, 2009), there is little known about how $\mathrm{mAChRs}$ influence synaptic plasticity in mPFC. Recent data indicate that pharmacological $\mathrm{mAChR}$ activation enhances glutamatergic transmission in mPFC (Shirey et al., 2009) or produces 
LTD (Wang and Yuan, 2009; Huang and Hsu, 2010). In this study, we first confirm that activation of mAChRs can trigger LTD in mPFC (Wang and Yuan, 2009; Huang and Hsu, 2010). Second, we show for the first time that the $\mathrm{M}_{1}$ potentiator BQCA enhances LTD. Third, we demonstrate the induction of a form of activity-dependent LTD that relies solely on release of endogenous acetylcholine. These results are the first to demonstrate that endogenous acetylcholine released by synaptic stimulation is sufficient to produce long-term plasticity of AMPA-mediated transmission in $\mathrm{mPFC}$.

\section{Materials and Methods}

Tissue slices. Methods for obtaining whole-cell voltage-clamp recordings were similar to those described previously (Caruana and Chapman, 2008; Griffiths et al., 2008; Garden et al., 2009) and experiments were conducted in accordance with the UK Animals (Scientific Procedures) Act 1986. Briefly, male Dark Agouti rats (P30 on day of use; B and K Universal) were anesthetized with isoflurane, decapitated, and their brains were rapidly removed and transferred into cold $\left(\sim 4^{\circ} \mathrm{C}\right)$ artificial CSF (ACSF) saturated with 95\% $\mathrm{O}_{2}$ and 5\% $\mathrm{CO}_{2}$ containing (in mM) 124 $\mathrm{NaCl}, 3 \mathrm{KCl}, 26 \mathrm{NaHCO}_{3}, 1.25 \mathrm{NaH}_{2} \mathrm{PO}_{4}, 1 \mathrm{MgSO} 4,10$ D-glucose, and 2 $\mathrm{CaCl}_{2}$. Unless stated, all reagents were obtained from Sigma (Sigma Aldrich). Coronal slices ( $400 \mu \mathrm{m}$ thick) were cut using a vibratome (DTK1000 , Ted Pella), and slices recovered for $\geq 1 \mathrm{~h}$ at $22-24^{\circ} \mathrm{C}$. Slices were transferred individually to a recording chamber and visualized using an upright microscope (Eclipse E600 FN, Nikon Instruments) equipped with differential interference contrast optics, a $40 \times$ water-immersion objective, and a near-infrared camera (C7500-11, Hamamatsu Photonics). Submerged slices were superfused with oxygenated ACSF at a rate of $2.0 \mathrm{ml} / \mathrm{min}$ at room temperature $\left(22-24^{\circ} \mathrm{C}\right)$. Slices containing the medial prefrontal cortex were taken from sections located within $2.2-4.2 \mathrm{~mm}$ anterior to bregma (Paxinos and Watson, 1998).

Stimulation and recording. Patch recording pipettes for whole-cell recordings were prepared from borosilicate glass $(1.5 \mathrm{~mm}$ outer diameter, 2.0-3.5 M $\Omega$; Harvard Apparatus) using a horizontal puller (P-97, Sutter Instrument) and were filled with a solution containing (in $\mathrm{mM}$ ) 130 $\mathrm{CsMeSO}_{4}, 8 \mathrm{NaCl}, 10 \mathrm{HEPES}, 0.5$ EGTA, $4 \mathrm{Mg}$-ATP, $0.3 \mathrm{Na}-\mathrm{GTP}$, and 5 QX-314- $\mathrm{Cl}$ (pH adjusted to $\sim 7.25$ with $\mathrm{CsOH} ; 280-290 \mathrm{mOsm}$ ). Pipettes were placed in contact with somata of layer $\mathrm{V}$ neurons and gentle suction was applied under voltage clamp to form a tight seal (1-3 G $\Omega$ ). Whole-cell configuration was achieved by increased suction, and experiments began after cells stabilized (typically within 10-15 min following break-in). Voltage-clamp recordings $\left(V_{\mathrm{h}}=-70 \mathrm{mV}\right)$ were obtained using an Axopatch 200B amplifier (Molecular Devices) and displayed on a computer monitor using the software package WinLTP (v1.11b for Windows; WinLTP). Recordings were filtered at $5 \mathrm{kHz}$ and digitized at $20 \mathrm{kHz}$ (Digidata 1322A, Molecular Devices) for storage on computer hard disk (using a Pentium-based Windows PC; Viglen). No correction was applied to compensate for liquid junction potentials. Only cells with a series resistance $\left(R_{\mathrm{s}}\right)<25 \mathrm{M} \Omega$ and a $<20 \%$ change in $R_{\mathrm{s}}$ from baseline during the course of an experiment were included for analysis. Two concentric bipolar stimulating electrodes (CBAPB50, FHC) were positioned along the layer I-II border at sites dorsal to and ventral to the recording electrode located in layer V (Fig. $1 \mathrm{~A}$ ). Synaptic responses were evoked with $0.1 \mathrm{~ms}$ constant current pulses delivered using two stimulus isolation units (Model DS3, Digitimer), and stimulation intensity was adjusted to evoke synaptic currents $\sim 75 \%$ of maximal amplitude (range; $75-300 \mu \mathrm{A}$ ). Single test pulses or pairs of stimulation pulses (with a $50 \mathrm{~ms}$ interpulse interval) were delivered alternately to each stimulation site at a frequency of $0.016 \mathrm{~Hz}$ to evoke EPSCs. Attempts to induce activitydependent LTD in the prelimbic region were made by delivering lowfrequency stimulation (LFS) to one of the two stimulation sites (selected at random) in the superficial layers. The second stimulation site served as an unconditioned control pathway in these experiments. LFS protocols consisted of 300 or 450 pairs of stimulation pulses (with a 50 ms interpulse interval) delivered to layer I/II at a frequency of $1 \mathrm{~Hz}$, or 450 single-pulses delivered at $1 \mathrm{~Hz}$. Test stimulation and LFS protocols were configured and controlled using WinLTP. All neurons included for anal- ysis were identified visually as pyramidal cells based on the shape of somata and were located between $\sim 550$ and $850 \mu \mathrm{m}$ from the pial surface of the slice in layer $\mathrm{V}$.

Data analysis. Evoked synaptic currents were analyzed using the software applications WinLTP and AxoGraph X (v1.3.5 for Mac; AxoGraph Scientific). Peak amplitudes of EPSCs were measured relative to the prestimulus baseline ( $8-2 \mathrm{~ms}$ period before stimulation pulse), and pairedpulse facilitation was determined by expressing the amplitude of the second response as a proportion of the amplitude of the first response. Input resistance $\left(R_{\text {in }}\right)$ was calculated by measuring the amplitude of the steady-state current evoked during a $-5 \mathrm{mV}$ voltage step (50 ms duration) delivered $100 \mathrm{~ms}$ before test stimulation, and $R_{\mathrm{s}}$ was calculated by measuring the peak amplitude of the fast capacitive transient observed at the onset of the voltage step. The amplitude (A) and membrane time constant $(\tau)$ of EPSCs were measured based on the average of five consecutive responses recorded at different times during an experiment (specified below). The membrane time constant was first calculated by fitting the decay of the synaptic current with two exponentials using Clampfit (v10.2 for Windows; Molecular Devices). The value of the weighted time constant $(\tau \mathrm{w})$ was then calculated using the following: $\tau \mathrm{w}=\tau 1 * \mathrm{~A} 1 /(\mathrm{A} 1+\mathrm{A} 2)+\tau 2 * \mathrm{~A} 2 /(\mathrm{A} 1+\mathrm{A} 2)$ (Bartlett et al., 2007). Concentration-response curves were generated with Prism (v5.0d for Mac; GraphPad Software) and fit using the least-squares (ordinary) method. Comparisons of curve-fits used to determine $\mathrm{EC}_{50}$ values were made using sum-of-squares $F$ tests. The coefficient of variation $\left(1 / C V^{2}\right.$; where $C=$ mean and $V=\mathrm{SD}$ ) was calculated on the mean amplitude of responses obtained during 10 min epochs of stable recordings of EPSCs using Excel (v2011 for Mac; Microsoft). The stability of responses was first confirmed by testing the slope of a regression line fit through data points included for $1 / C V^{2}$ analyses, and results for $1 / C V^{2}$ analyses were expressed as a ratio of the baseline for plotting. The effects of bath or intracellularly applied drugs during pharmacological experiments were assessed on the amplitude of averaged EPSCs obtained during 5 min epochs recorded at different times during an experiment (latencies specified below). All data were expressed as the mean \pm SEM and were normalized to baseline recordings for plotting. Changes in response properties were assessed with Prism using (where appropriate) paired or unpaired samples $t$ tests, one-way ANOVAs, or repeated-measures ANOVAs. Post hoc comparisons were made using the Bonferroni method with an $\alpha$ level of $p<0.05$.

Pharmacology. Unless stated, all compounds used for pharmacological experiments were obtained from Tocris Bioscience and prepared as concentrated stock solutions (typically $10-50 \mathrm{~mm}$ ) by dilution in (where appropriate) either distilled water or dimethyl sulfoxide and stored at $-20^{\circ} \mathrm{C}$ until required. To examine the role of the cholinergic system in modulating synaptic transmission in mPFC, multiple concentrations of the nonselective cholinergic agonist (2-Hydroxyethyl) trimethylammonium chloride carbamate (carbachol; from $10 \mathrm{~nm}$ up to $100 \mu \mathrm{M}$ ) were bath applied. In some experiments the acetylcholinesterase inhibitors (3aS)-cis-1,2,3,3a,8,8aHexahydro-1,3a,8-trimethylpyrrolo[2,3-b]indol-5-ol methylcarbamate hemisulfate (physostigmine; $2 \mu \mathrm{M}$ ) or 1,5-Bis(4-allyldimethylammoniumphenyl)pentan-3-one dibromide (BW 284c51; $200 \mathrm{~nm}$; obtained from Sigma) were used. The contribution of muscarinic receptors to carbacholmediated changes in basal synaptic transmission was assessed by using the nonselective muscarinic receptor antagonists (a,S)-a-(Hydroxymethyl) benzeneacetic acid (1a,2b,4b,5a,7b)-9-methyl-3-oxa-9-azatricyclo[3.3.1.02, 4]non-7-yl ester hydrobromide (scopolamine; $10 \mu \mathrm{M}$ ) or (endo,syn)-( \pm )-3(3-Hydroxy-1-oxo-2-phenylpropoxy)-8-methyl-8-(1-methylethyl)-8azonia bicyclo[3.2.1] octane bromide (atropine; $1 \mu \mathrm{M}$ ), the $\mathrm{M}_{1}$ antagonists 5,11-Dihydro-11-[(4-methyl-1-piperazinyl)acetyl]-6 H-pyrido[2,3-b] $[1,4]$ benzodiazepin-6-one dihydrochloride (pirenzepine; $0.5 \mu \mathrm{M}$ ), or $\mathrm{N}$-[3Oxo-3-[4-(4-pyridinyl)-1-piper azinyl]propyl]-2,1,3-benzothiadiazole-4sulfonamide (VU0255035; $10 \mu \mathrm{M}$ ), the $\mathrm{M}_{1}$ receptor agonists 4-[[[(3Chlorophenyl)amino] carbonyl] oxy]- $N, N, N$-trimethy 1-2-butyn-1aminium chloride (McN-A-343; $3 \mu \mathrm{M})$, or cis-2-Methylspiro[1,3oxathiolane-5, $3^{\prime}$-quinuclidine] hydrochloride (AF102B; $100 \mu \mathrm{M}$ ), or the $\mathrm{M}_{1}$-selective positive allosteric modulator 1-(4-Methoxybenzyl)-4-oxo-1,4dihydro-3-quinoline carboxylic acid (BQCA; $10 \mu \mathrm{m}$; obtained from Enzo Life Sciences). The involvement of NMDA receptors (NMDARs) and 
A Electrode Placement

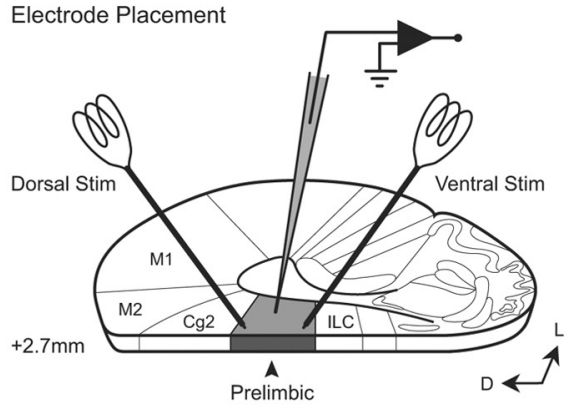

$\mathbf{B}_{1}$

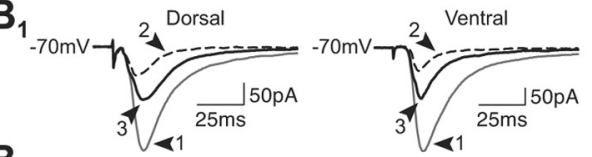

B
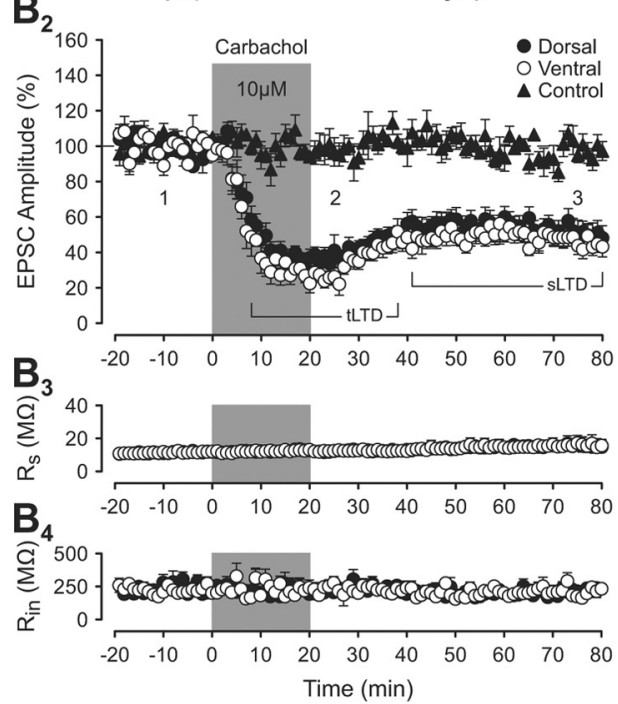

C

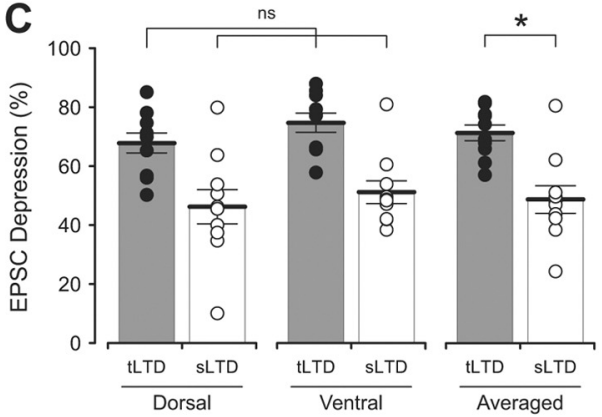

$\mathrm{D}_{1}$
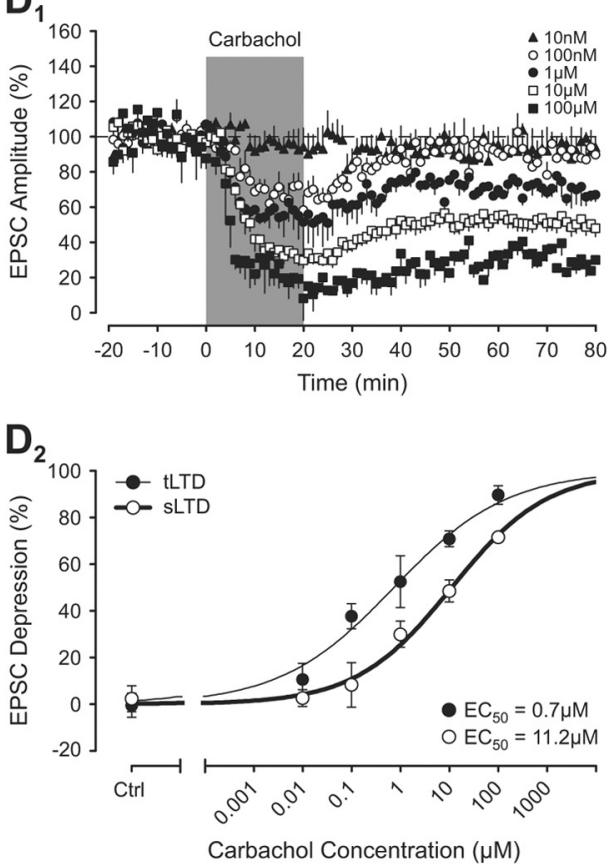

Figure 1. Bath application of carbachol induces LTD of EPSCs in the prelimbic region. A, Schematic diagram illustrating the placement of stimulating and recording electrodes in coronal slices containing the mPFC. Two stimulating electrodes are positioned along the layer I/II border at sites dorsal to (Dorsal Stim) and ventral to (Ventral Stim) the recording electrode in layer V (ILC, infralimbic cortex; $\mathrm{Cg} 2$, cingulate cortex; $\mathrm{M}_{1}$, primary motor cortex; $\mathrm{M}_{2}$, secondary motor cortex). Image modified from the atlas of Paxinos and Watson (1998) at a position $+2.7 \mathrm{~mm}$ anterior to bregma. $\boldsymbol{B}$, EPSCs are depressed by bath application of $10 \mu \mathrm{m}$ carbachol. Numbered traces in $\boldsymbol{B}_{1}$ show representative EPSCs evoked at the time points indicated by the corresponding numbers in $\boldsymbol{B}_{2}$ for the dorsal and ventral stimulation sites. Mean data in $\boldsymbol{B}_{\mathbf{2}}$ highlight two distinct phases to the depression of EPSCs induced by carbachol: a potent but transient depression of responses lasting $\sim 30$ min (tLTD) followed by recovery to a sustained depression of transmission (sLTD). Bath application of carbachol is marked by the gray bar and data are expressed as a percentage change in the baseline amplitude of EPSCS (mean \pm SEM) in this and subsequent figures, unless noted otherwise. Separate time-matched control data (filled triangles) are superimposed in $\boldsymbol{B}_{\mathbf{2}}$ and indicate that EPSCs are stable for $100 \mathrm{~min}$ in the absence of any pharmacological treatment. Note that $R_{5}\left(\boldsymbol{B}_{3}\right)$ and $R_{\text {in }}\left(\boldsymbol{B}_{4}\right)$ are unaffected by carbachol. $\boldsymbol{C}$, There is no difference in the amount of tLTD and sLTD induced by carbachol when comparing responses evoked by stimulating either the dorsal or ventral site (ns, not significant; ${ }^{*} p<0.05$ ). Data points for individual experiments are superimposed on summary histograms in this and subsequent figures. $\boldsymbol{D}$, Carbachol has concentration-dependent effects on the amplitude of EPSCs evoked in the prelimbic region. A summary of results for experiments assessing the effects of increasing concentrations of carbachol (from $10 \mathrm{~nm}$ to $100 \mu \mathrm{m}$ ) on evoked synaptic responses is shown in $\boldsymbol{D}_{1}$. $\boldsymbol{D}_{2}$, Concentration-response curves generated from data in $\boldsymbol{D}_{1}$ show the depression of EPSCs relative to control responses (Ctrl) averaged over 5 min epochs during the peak of tLTD (filled circles) and the last 5 min of recording (sLTD; open circles) for the five concentrations of carbachol tested. The $\mathrm{EC}_{50}$ for carbachol is $0.7 \mu \mathrm{m}$ for $\mathrm{tLTD}$ and $11.2 \mu \mathrm{m}$ for sLTD.

metabotropic glutamate receptors (mGluRs) was examined using D- (-)-2Amino-5-phosphonopentanoic acid (D-AP5; $50 \mu \mathrm{M})$ or (5R,10S)-(-)-5Methyl-10,11-dihydro-5H-dibenzo[a,d]cylcohepten-5,10-imine maleate (MK-801; 3 mm; loaded intracellularly), and (2S)-2-Amino-2-[(1S,2S)-2carboxycycloprop-1-yl]-3-(xanth-9-yl) propanoic acid (LY341495; 100 $\mu \mathrm{M})$, respectively, and the role of intracellular $\mathrm{Ca}^{2+}$ was assessed by loading cells with $10 \mathrm{~mm}$ 1,2-Bis(2-aminophenoxy)ethane- $N, N, N^{\prime}, N^{\prime}$-tetraacetic acid (BAPTA). Involvement of protein kinase $\mathrm{C}$ (PKC) was determined using 3-[3-[2,5-Dihydro-4-(1-methyl-1 $H$-indol-3-yl)-2,5-dioxo- $1 H$ pyrrol-3-yl]-1 $H$-indol-1-yl]propyl carbamimidothioic acid ester mesylate (Ro-31-8220; $2.5 \mu \mathrm{m}$; bath applied), 3-[(8S)-8-[(Dimethylamino)methyl]6,7,8,9-tetrahydropyr ido[1,2-a]indol-10-yl]-4-(1-methyl-1 $H$-indol-3-yl)$1 \mathrm{H}$-pyrrole-2,5-dione hydrochloride (Ro-32-0432; $10 \mu \mathrm{M}$; loaded intracellularly) or the pseudosubstrate peptide inhibitor of PKC (PKC (1936); $10 \mu \mathrm{M}$; loaded intracellularly), and the contribution of nitric oxide to carbachol-mediated changes in EPSCs was assessed by continuous perfusion of the nitric oxide synthase inhibitor NG-Nitro-L-arginine methyl ester hydrochloride (L-NAME; $50 \mu \mathrm{M}$ ).

\section{Results}

\section{Activation of acetylcholine receptors induces LTD in the} prelimbic region

EPSCs were evoked in layer V pyramidal cells following intracortical stimulation of superficial layer afferents for both the dorsal and ventral stimulation sites. Placement of the stimulating electrodes in layers I/II was determined based on the convergence and density of afferent fibers originating from the hippocampus (Jay and Witter, 1991) and perirhinal cortex (Delatour and Witter, 2002) that terminate within the prelimbic region of the mPFC 
(Hoover and Vertes, 2007). Additionally, anatomical data suggest that cholinergic projections to the $\mathrm{mPFC}$ are most dense in the superficial layers (Mrzljak et al., 1995). Figure $1 A$ shows a schematic diagram illustrating the placement of stimulating and recording electrodes in the MPFC, and example EPSCs are shown in Figure $1 B_{1}$ (gray traces; recorded during baseline and indicated by the number 1 ). To determine whether activation of cholinergic receptors modulates basal synaptic transmission in the prelimbic region, the nonselective cholinergic agonist carbachol (10 $\mu \mathrm{M})$ was bath applied to slices of medial prefrontal cortex for 20 min and then washed out with normal ACSF $(n=10)$. As shown in Figure $1 B_{2}$, carbachol induced a rapid and potent transient depression (tLTD) in the amplitude of EPSCs (lasting for $\sim 30$ $\mathrm{min}$ ), which partially recovered to a steady-state sustained longterm depression of synaptic transmission (sLTD), and persisted for the remainder of the experiment. Responses were reduced to $32.0 \pm 3.4 \%$ and $25.1 \pm 3.2 \%$ of baseline levels during the peak of the tLTD phase for the dorsal (filled circles) and ventral (open circles) stimulation sites, respectively (tLTD phase defined as the 5 min period of maximal inhibition induced by carbachol), and were significantly depressed relative to responses evoked during separate time-matched control experiments (Fig. $1 B_{2}$, filled triangles, $n=4 ; F_{(2,21)}=63.94, p<0.0001$; dorsal, Bonferroni, $p<$ 0.0001 ; ventral, Bonferroni, $p<0.0001)$. Further, synaptic responses remained significantly depressed at $53.7 \pm 5.8 \%$ and $48.7 \pm 3.9 \%$ of baseline during the last $5 \mathrm{~min}$ of the experiment (sLTD phase) for the dorsal and ventral stimulation sites, respectively, when compared with control responses $\left(F_{(2,21)}=15.96\right.$, $p<0.0001$; dorsal, Bonferroni, $p<0.001$; ventral, Bonferroni, $p<0.0001)$. The magnitude of tLTD and sLTD induced by carbachol did not differ between dorsal and ventral stimulation sites (Fig. $1 B, C$; tLTD dorsal vs ventral, Bonferroni, $p=0.54$; sLTD dorsal vs ventral, Bonferroni, $p=1.00$ ). Therefore, data obtained for each site were averaged for subsequent experiments described below. The depression of EPSCs was also significantly larger during tLTD than during sLTD (Fig. $1 C$; averaged, $t_{(9)}=5.74, p<$ 0.001 ). The effects of carbachol were not associated with changes in the weighted time constant of EPSCs recorded during tLTD or sLTD ( $n=9$; baseline, $100.0 \pm 26.1 \%$; tLTD, $116.8 \pm 30.5 \%$; $\operatorname{sLTD} 101.0 \pm 27.7 \% ; F_{(2,16)}=1.25, p=0.31$; data not shown). Additionally, there was no significant change in $R_{\mathrm{s}}$ or $R_{\mathrm{in}}$ (Fig. $1 B_{3}, B_{4}$, respectively; $R_{\mathrm{s}}, t_{(9)}=2.09, p=0.07 ; R_{\mathrm{in}}, F_{(2,18)}=0.84$, $p=0.45)$, indicating that the tLTD and SLTD of EPSCs induced by carbachol did not result from changes in electrical access or membrane resistance.

\section{The effects of carbachol on synaptic responses are concentration dependent}

Twenty minute application of $10 \mathrm{nM}$ carbachol (Fig. $1 D_{1}$, filled triangles; $n=4$ ) did not induce any significant tLTD or sLTD of synaptic responses when compared with time-matched control experiments $\left(n=4\right.$; $\operatorname{tLTD}, t_{(6)}=1.38, p=0.22$; $\operatorname{sLD} t_{(6)}=0.40$, $p=0.71$ ). Bath application of $100 \mathrm{~nm}$ carbachol (Fig. $1 D_{1}$, open circles; $n=5$ ) induced tLTD of EPSCs, but no lasting depression of synaptic transmission ( $\operatorname{tLTD}, t_{(7)}=5.55, p<0.001$; $\operatorname{sLD} t_{(7)}=$ $0.70, p=0.51$ ). However, application of $1 \mu \mathrm{M}$ (filled circles; $n=$ 3), $10 \mu \mathrm{M}$ (open squares; $n=10$ ), or $100 \mu \mathrm{M}$ carbachol (filled squares; $n=3$ ) induced tLTD and sLTD of EPSCs in the MPFC in a concentration-dependent manner $\left(1 \mu \mathrm{M}, \mathrm{tLTD}, t_{(5)}=5.10, p<\right.$ $0.01, \operatorname{sLTD} t_{(5)}=3.64, p<0.05 ; 10 \mu \mathrm{M}$, tLTD, $t_{(12)}=11.70, p<$ 0.0001 , sLTD, $t_{(12)}=5.820, p<0.0001 ; 100 \mu \mathrm{M}$, tLTD, $t_{(5)}=13.06$, $p<0.0001$, sLTD, $\left.t_{(5)}=10.47, p<0.0001\right)$. Results of nonlinear curve fitting for concentration-responses curves generated by comparing tLTD and sLTD of EPSCs induced by carbachol (Fig. $1 D_{2}$ ) revealed a significant difference between the fit of the curves for $\operatorname{tLTD}$ and $\operatorname{sLTD}\left(F_{(2,54)}=18.53, p<0.0001\right)$. Based on the curve-fits, the $\mathrm{EC}_{50}$ value for tLTD was determined to be $0.7 \mu \mathrm{M}$, which differed from the value of $11.2 \mu \mathrm{M}$ obtained for sLTD. Furthermore, there was a positive linear correlation between the amount of tLTD and sLTD induced by increasing concentrations of carbachol $\left(R^{2}=0.74\right.$; data not shown $)$.

\section{Varying carbachol duration and stimulation parameters}

Levels of tLTD and sLTD were compared following bath application of $10 \mu \mathrm{M}$ carbachol for a duration of either 5 (open circles; $n=5$ ), 20 (gray filled circles; $n=10$ ), or 40 min (black filled circles; $n=5$ ) (Fig. $2 A_{1}$ ). EPSCs were depressed to $32.2 \pm 2.8 \%$, $28.6 \pm 2.7 \%$, and $22.7 \pm 3.7 \%$ of baseline during tLTD following 5,20 , or $40 \mathrm{~min}$ application of carbachol, respectively, and tLTD did not differ significantly between the three application times tested (Fig. $2 \mathrm{~A}_{2}$; tLTD, $F_{(2,17)}=1.80, p=0.20$ ). In addition, sLTD was $53.8 \pm 7.3 \%, 52.2 \pm 4.2 \%$, and $45.6 \pm 5.6 \%$ of baseline levels following 5, 20, or $40 \mathrm{~min}$ of carbachol application, respectively, and sLTD did not differ significantly across the three application times (Fig. $2 \mathrm{~A}_{2}$; sLTD, $F_{(2,17)}=0.51, p=0.61$ ). These data indicate that varying the application time of carbachol had no significant effect on the magnitude of tLTD and sLTD induced in the medial prefrontal cortex.

To assess whether synaptic stimulation was required for the induction of carbachol-mediated LTD, the delivery of test stimulation to one input was paused for $50 \mathrm{~min}$ at the start of carbachol application (10 $\mu \mathrm{M}$ for $20 \mathrm{~min}$ ) and levels of sLTD were compared, after synaptic stimulation had resumed, to levels of sLTD in the uninterrupted input (Fig. $2 B_{1} ; n=4$ ). Synaptic responses were depressed by carbachol to $55.2 \pm 4.3 \%$ of baseline in the nonstimulated input; this depression was not significantly different from the sLTD of EPSCs induced by carbachol in the alternate input that received continuous test stimulation throughout the experiment $\left(57.2 \pm 3.5 \%\right.$; Fig. $2 B_{2}$; $s L T D, t_{(3)}=0.42, p=0.70$ ). These data suggest, therefore, that constant synaptic drive is not required for the induction of carbachol-mediated LTD in the prelimbic region.

Levels of tLTD and sLTD induced by application of $10 \mu \mathrm{M}$ carbachol were compared following stimulation of either superficial layer (LI/II) or deep layer (LV) inputs to layer V pyramidal cells (Fig. $2 C_{1} ; n=5$ ). EPSCs induced by stimulation of the superficial layers were depressed to $28.2 \pm 4.0 \%$ and $53.8 \pm 3.1 \%$ of baseline for tLTD and sLTD, respectively. Responses evoked by stimulation of deep layer inputs to the same cells were depressed to $32.7 \pm 7.0 \%$ and $62.5 \pm 4.8 \%$ of baseline for tLTD and sLTD, respectively. Levels of tLTD and SLTD induced by carbachol did not differ significantly when comparing responses evoked by superficial or deep layer stimulation (Fig. $2 C_{2}$; tLTD, $t_{(4)}=0.69$, $p=0.53 ;$ sLTD $\left.t_{(4)}=1.74, p=0.16\right)$.

\section{Activation of muscarinic receptors is required for carbachol-mediated LTD}

To determine the involvement of mAChRs in tLTD and sLTD of EPSCs induced by carbachol, the nonselective mAChR antagonist scopolamine $(10 \mu \mathrm{M})$ was coapplied with $10 \mu \mathrm{M}$ carbachol $(n=5)$. Application of scopolamine alone for $15 \mathrm{~min}$ had no significant effect on basal synaptic transmission but blocked both the tLTD and sLTD of synaptic responses typically induced by carbachol (Fig. $3 A_{1}$ ). In the presence of scopolamine, the amplitude of EPSCs was reduced by carbachol to $87.8 \pm 10.0 \%$ and $89.1 \pm 7.6 \%$ of baseline for tLTD and sLTD, respectively, but this 
reduction was not significant when compared with responses evoked during separate time-matched control experiments (tLTD, Bonferroni, $p=1.00$; sLTD, Bonferroni, $p=1.00)$. In addition, levels of tLTD and sLTD in slices treated with scopolamine were significantly less than those observed in control slices that received only carbachol (tLTD, $F_{(2,16)}=$ 47.35, $p<0.0001$, Bonferroni, $p<0.0001$; sLTD, $F_{(2,16)}=19.15, p<0.0001$, Bonferroni, $p<0.001)$. Together, these findings indicate that both the tLTD and SLTD of EPSCs induced by carbachol are mediated by activation of mAChRs. Interestingly, scopolamine had no effect on established sLTD (Fig. $3 A_{2}$, filled circles; $n=4$ ); responses remained depressed at $59.3 \pm$ $7.0 \%$ of baseline during $\operatorname{sLTD}\left(F_{(2,18)}=\right.$ 41.52, $p<0.0001$, Bonferroni, $p<$ 0.0001 ), and the level of sLTD did not differ significantly from levels in carbacholtreated control slices not exposed to scopolamine (Fig. $3 A_{2}$, open circles; $n=7$; Bonferroni, $p=1.00)$.

To further confirm that the tLTD and sLTD of EPSCs induced by carbachol are, indeed, mediated by activation of muscarinic receptors, an additional nonselective muscarinic receptor antagonist, atropine $(1 \mu \mathrm{M})$, was tested (Fig. 3B, filled circles; $n=4)$. Similar to results obtained with scopolamine, coapplication of atropine with carbachol blocked both the tLTD and sLTD of EPSCs normally observed with carbachol alone. Responses remained stable at $100.3 \pm 6.3 \%$ and $103.5 \pm 3.8 \%$ of baseline for tLTD and sLTD, respectively, and EPSCs were significantly larger than those obtained following bath application of carbachol alone (tLTD, $F_{(2,18)}=89.82, p<0.0001$, Bonferroni, $p<0.0001$; sLTD, $F_{(2,18)}=$ 46.92, $p<0.0001$, Bonferroni, $p<0.0001)$. Similar to results obtained with scopolamine, the magnitude of tLTD and sLTD did not differ significantly from timematched control responses following coapplication of atropine and carbachol (tLTD, Bonferroni, $p=1.00$; sLTD, Bonferroni, $p=1.00$ ).

\section{$M_{1}$ receptor activation is required for sustained LTD in the prelimbic region}

Of the five known subtypes of mAChRs found throughout the brain $\left(M_{1}\right.$ to $\left.M_{5}\right)$ (Levey, 1996; Eglen, 2006), the $M_{1}$ receptor has been shown to play a critical role in learning and memory functions mediated by the mPFC (Shirey et al., 2009). To assess contributions of $\mathrm{M}_{1}$ receptors to the carbachol-mediated tLTD and sLTD of EPSCs, the selective $M_{1}$ receptor antagonist pirenzepine was coapplied with $10 \mu \mathrm{M}$ carbachol $(0.5 \mu \mathrm{M} ; n=5)$ (Massey et al., 2001). Under these conditions (Fig. $3 C_{1} ; n=5$ ), responses were reduced by carbachol to $53.6 \pm 7.2 \%$ of baseline levels during tLTD, and although the amplitude of EPSCs was depressed significantly relative to control responses $\left(F_{(2,16)}=46.79, p<\right.$
0.0001, Bonferroni, $p<0.001$ ), the amount of tLTD was significantly less than that observed during separate control experiments with carbachol alone (Bonferroni, $p<0.01$ ). Interestingly, carbachol reduced the amplitude of EPSCs during sLTD to $74.8 \pm 4.3 \%$ of baseline levels in the presence of pirenzepine (Fig. $\left.3 C_{1}\right)$, but this reduction was not significantly different from untreated controls $\left(F_{(2,16)}=19.30, p<0.0001\right.$, Bonferroni, $p=$ $0.06)$, and the amount of sLTD was significantly less than the amount of sLTD induced by carbachol alone (Bonferroni, $p<$ $0.05)$. Together, these data indicate that there is a significant $M_{1}$ mediated component that contributes to the lasting sustained depression of EPSCs induced by carbachol.

To further evaluate the role of $M_{1}$ receptors, additional experiments were also performed using the highly selective $M_{1}$ receptor antagonist, VU0255035 (Sheffler et al., 2009). Coapplication 

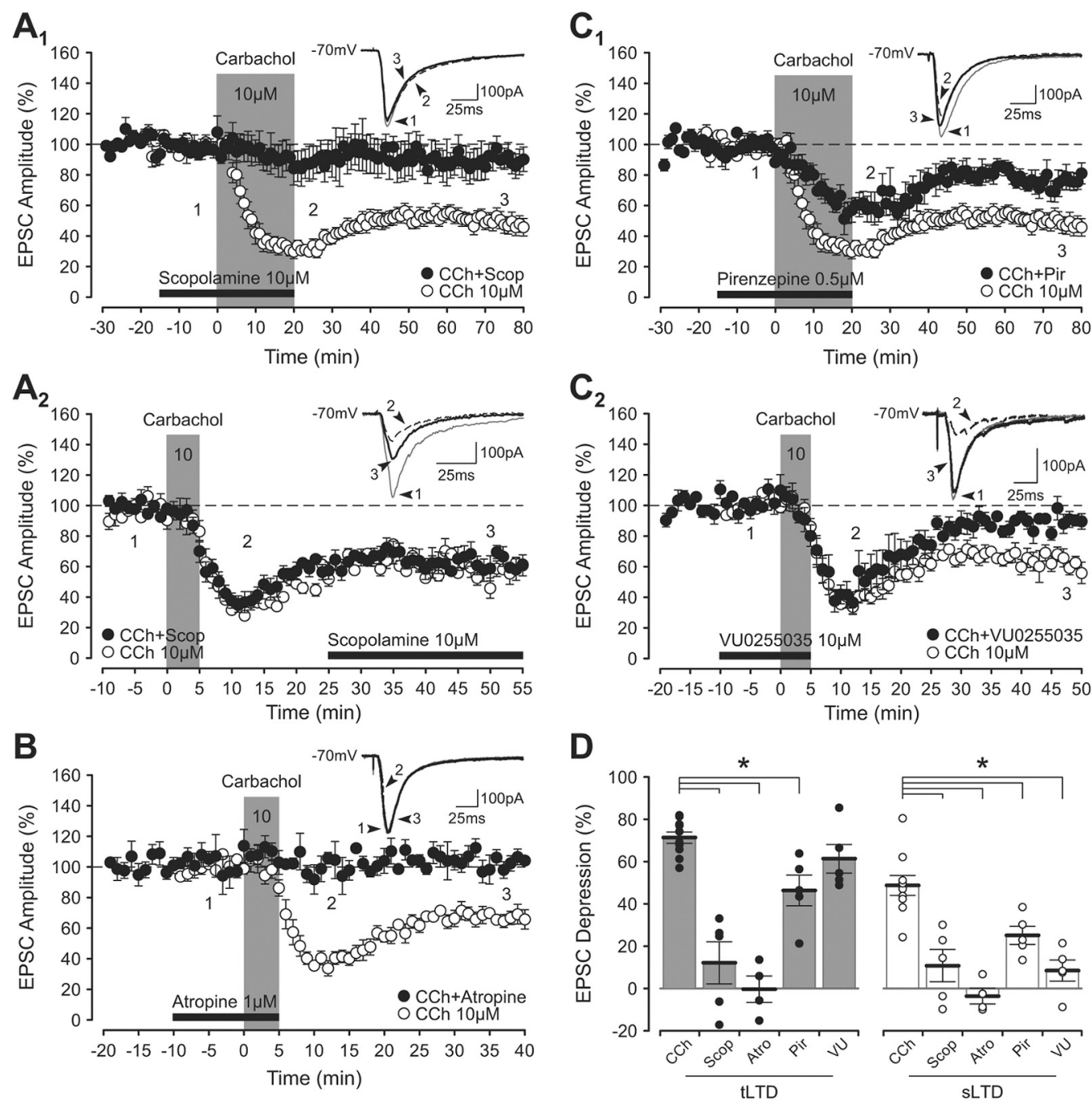

Figure 3. Carbachol-mediated LTD of EPSCs in the prelimbic region requires activation of muscarinic receptors. A, Application of the nonselective muscarinic receptor antagonist scopolamine (10 $\mu \mathrm{M}$ ) blocks both the LLTD and SLTD induced by carbachol. Group data in $A_{1}$ show the block of carbachol-LTD by scopolamine (filled circles) plotted together with control data for separate experiments in which $10 \mu \mathrm{m}$ carbachol was applied alone (open circles). The black bar denotes the latency and duration of scopolamine bath application. Inset traces show representative EPSCs recorded at the time points indicated by the numbers. Interestingly, the sLTD of EPSCs is not reversed by scopolamine once carbachol-mediated LTD has already been established $\left(\boldsymbol{A}_{2}\right)$. $\boldsymbol{B}$, Coapplication of a different nonselective muscarinic receptor antagonist, atropine $(1 \mu \mathrm{M})$, also blocked both the LLTD and SLTD of EPSCs induced by carbachol. C, The carbachol-mediated LTD of EPSCs involves activation of $\mathrm{M}_{1}$ receptors. Bath application of the $\mathrm{M}_{1}$ antagonist pirenzepine $(0.5 \mu \mathrm{m})$ significantly attenuates both the tLTD and SLTD of EPSCs induced by carbachol $\left(\boldsymbol{C}_{7}\right)$. Note that there is still significant residual $\mathrm{LLTD}$ and $\mathrm{SLTD}$ induced by carbachol in the presence of pirenzepine. In contrast, the potent $M_{1}$ antagonist VU0255035 (10 $\left.\mu \mathrm{m}\right)$ blocked the SLTD of EPSCs induced by carbachol, but had no effect on the initial transient suppression $\left(\boldsymbol{C}_{2}\right)$. D , Histogram summarizing the depression of EPSCs induced by carbachol in the presence and absence of muscarinic receptor antagonists for both tLTD and $s L T D$. ${ }^{*} p<0.05$.

of $10 \mu \mathrm{M}$ VU0255035 with carbachol (Fig. $3 C_{2}$, filled circles; $n=$ 5) had no effect on the magnitude of tLTD when compared with control experiments with carbachol alone, but blocked the sustained depression of EPSCs. Responses were significantly reduced to $38.5 \pm 6.7 \%$ of baseline during tLTD when compared with time-matched controls $\left(F_{(2,19)}=86.52, p<0.0001\right.$, Bonferroni, $p<0.0001$ ), but did not differ significantly from controls during carbachol-induced tLTD (Bonferroni, $p=1.00$ ). The amplitude of EPSCs returned to $91.4 \pm 5.0 \%$ of baseline and did not differ significantly from time-matched controls $\left(F_{(2,19)}=35.06\right.$, $p<0.0001$, Bonferroni, $p=0.24)$, but was significantly greater than responses recorded following application of carbachol alone (Bonferroni, $p<0.001$ ). These data provide further evidence in favor of a role for $M_{1}$ receptors in mediating the sLTD of EPSCs induced by carbachol.

To further examine the role of $\mathrm{M}_{1}$ receptors in acetylcholinemediated LTD, the selective $\mathrm{M}_{1}$ receptor agonists $\mathrm{McN}-\mathrm{A}-343$ (3 $\mu \mathrm{M} ; n=4$; Fig. $\left.4 A_{1}\right)$ or AF102B $\left(100 \mu \mathrm{M} ; n=4\right.$; Fig. $\left.4 A_{2}\right)$ were bath applied to slices of mPFC. Perfusion of either McN-A-343 or AF102B induced a slow-onset depression of synaptic transmission that differed markedly from the biphasic depression induced by carbachol. Twenty-five minutes after the start of McN-A-343 application, the transient depression of EPSCs $(72.2 \pm 7.7 \%$ of baseline) was significantly less than the depression induced by carbachol alone (Fig. $4 B$; tLTD, $F_{(2,15)}=58.06, p<0.0001$, Bonferroni, $p<0.0001)$. A similar result was obtained for tLTD using AF102B (Fig. $4 B$; tLTD, $80.1 \pm 8.4 \%$ of baseline; $F_{(2,18)}=66.00$, $p<0.0001$, Bonferroni, $p<0.0001)$. In contrast, EPSCs were significantly depressed by $\mathrm{McN}-\mathrm{A}-343$ or $\mathrm{AF} 102 \mathrm{~B}$ to $54.8 \pm$ $18.1 \%$ and $58.3 \pm 4.7 \%$ of baseline, respectively during sLTD, when compared with time-matched control responses $(\mathrm{McN}-\mathrm{A}-$ $343, F_{(2,15)}=7.67, p<0.01$, Bonferroni, $p<0.05$; AF102B, $F_{(2,18)}=$ 51.48, $p<0.0001$, Bonferroni, $p<0.0001$ ), and the level of sLTD induced by either agonist did not differ significantly from levels induced by carbachol alone at a similar latency (Fig. $4 B$; sLTD: McNA-343, Bonferroni, $p=1.00$; AF102B, Bonferroni, $p=1.00$ ). These 

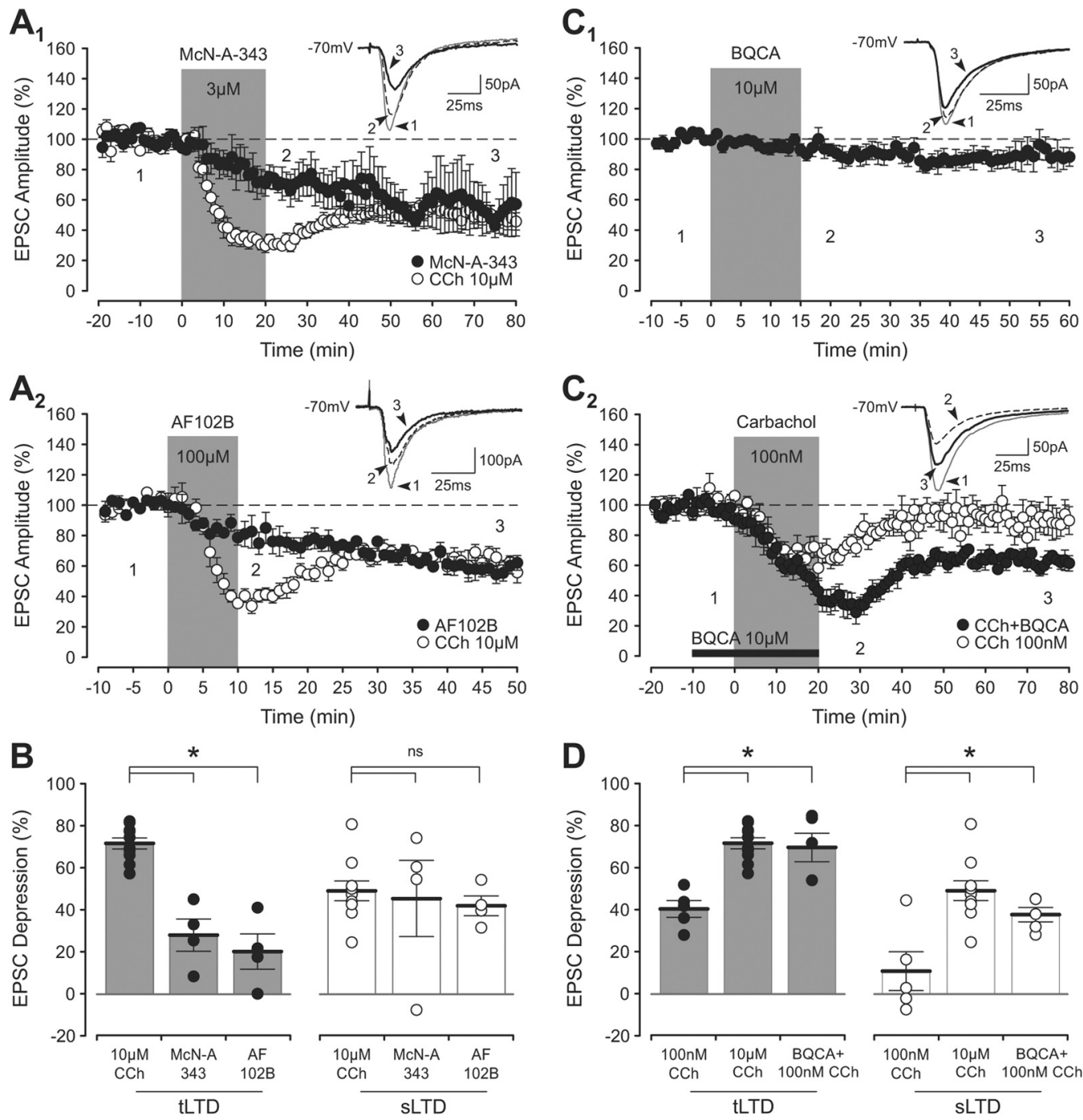

Figure 4. The sustained depression of EPSCS is mimicked by activation of $M_{1}$ receptors. $A$, Bath application of the selective $M_{1}$ receptor agonist MCN-A-343 (3 $\left.\mu \mathrm{M}\right)$ for 20 min induces sLTD of EPSCS $\left(A_{7}\right)$. Data for McN-A-343 (filled circles) are superimposed with data for separate experiments in which $10 \mu \mathrm{m}$ carbachol was applied alone (open circles). Note that McN-A-343 induces a similar sLTD as carbachol, but does not induce a rapid and potent transient suppression of synaptic responses. Similarly, bath application of another selective $\mathrm{M}_{1}$ receptor agonist, $A F 102 B(100 \mu \mathrm{M})$, also induces a slow-onset sLTD that lacks an initial tLTD phase $\left(\boldsymbol{A}_{2}\right)$. $\boldsymbol{B}$, Summary histogram comparing the depression of EPSCs induced by carbachol or by McN-A-343 or AF102B for both tLTD and sLTD. ${ }^{*} p<$ 0.05. $C$, Enhancing the sensitivity of $M_{1}$ receptors to carbachol converts a subthreshold concentration of carbachol into one which induces a lasting sLTD. The $M_{1}$-selective allosteric potentiator BQCA $(10 \mu \mathrm{m})$ has no significant effect on basal synaptic transmission in the $\operatorname{mPFC}\left(\boldsymbol{C}_{\mathbf{1}}\right)$, but greatly enhances the efficacy of a subthreshold $100 \mathrm{~nm}$ concentration of carbachol $\left(\boldsymbol{C}_{2}\right.$, filled circles). $\boldsymbol{D}$, The pairing of BQCA and $100 \mathrm{~nm}$ carbachol induces ILTD and SLTD of EPSCs that are statistically indistinguishable from results obtained with $10 \mu \mathrm{m}$ carbachol alone. ${ }^{*} p<0.05$.

results suggest that direct activation of $\mathrm{M}_{1}$ receptors by either $\mathrm{McN}$ A-343 or AF102B induces sLTD but not tLTD.

Enhancing the efficacy of $M_{1}$ receptors facilitates induction of carbachol-mediated LTD

An alternative approach to determine the contributions of muscarinic receptors to the depression of EPSCs is to use subtypeselective allosteric modulators for mAChRs that can enhance or suppress the functioning of target receptors by modulating responses mediated by traditional orthosteric binding. The compound BQCA is a positive allosteric modulator that is highly selective for $M_{1}$ receptors (Ma et al., 2009; Shirey et al., 2009). As shown in Figure $4 C_{1}$, bath application of BQCA alone for $15 \mathrm{~min}$ had no significant effect on basal synaptic transmission in the prelimbic region $(n=5)$. At a concentration of $100 \mathrm{nM}$, carbachol typically only induces tLTD of EPSCs and no sLTD of synaptic responses (Fig. $4 C_{2}$, open circles; $n=5$ ). However, pairing BQCA with $100 \mathrm{nM}$ carbachol significantly enhanced the effects of 100
nM carbachol alone (Fig. $4 C_{2}$, filled circles; $n=5$; tLTD, $F_{(2,17)}=$ $16.04, p<0.0001$; sLTD, $\left.F_{(2,17)}=10.55, p<0.01\right)$. EPSCs were significantly depressed to $30.5 \pm 6.7 \%$ and $62.6 \pm 3.4 \%$ of baseline during tLTD and SLTD, respectively, relative to data obtained with $100 \mathrm{~nm}$ carbachol alone (tLTD, Bonferroni, $p<0.001$; sLTD, Bonferroni, $p<0.05$ ), and levels of tLTD and SLTD induced by pairing BQCA and $100 \mathrm{~nm}$ carbachol were not significantly different from levels observed in experiments with $10 \mu \mathrm{M}$ carbachol alone (see summary in Fig. $4 D$; tLTD, Bonferroni, $p=1.00$; $\operatorname{sLTD}$, Bonferroni, $p=$ 0.58). Together, these findings further suggest that the sLTD of EPSCs induced by carbachol is mediated primarily through activation of $M_{1}$ muscarinic receptors.

\section{tLTD and sLTD are mediated by different receptors on opposite sides of the synapse}

The results listed above for experiments using selective $M_{1}$ receptor agonists, $\mathrm{M}_{1}$ allosteric modulators, and $\mathrm{M}_{1}$ antagonists strongly suggest that the sLTD of EPSCs induced by carbachol is 

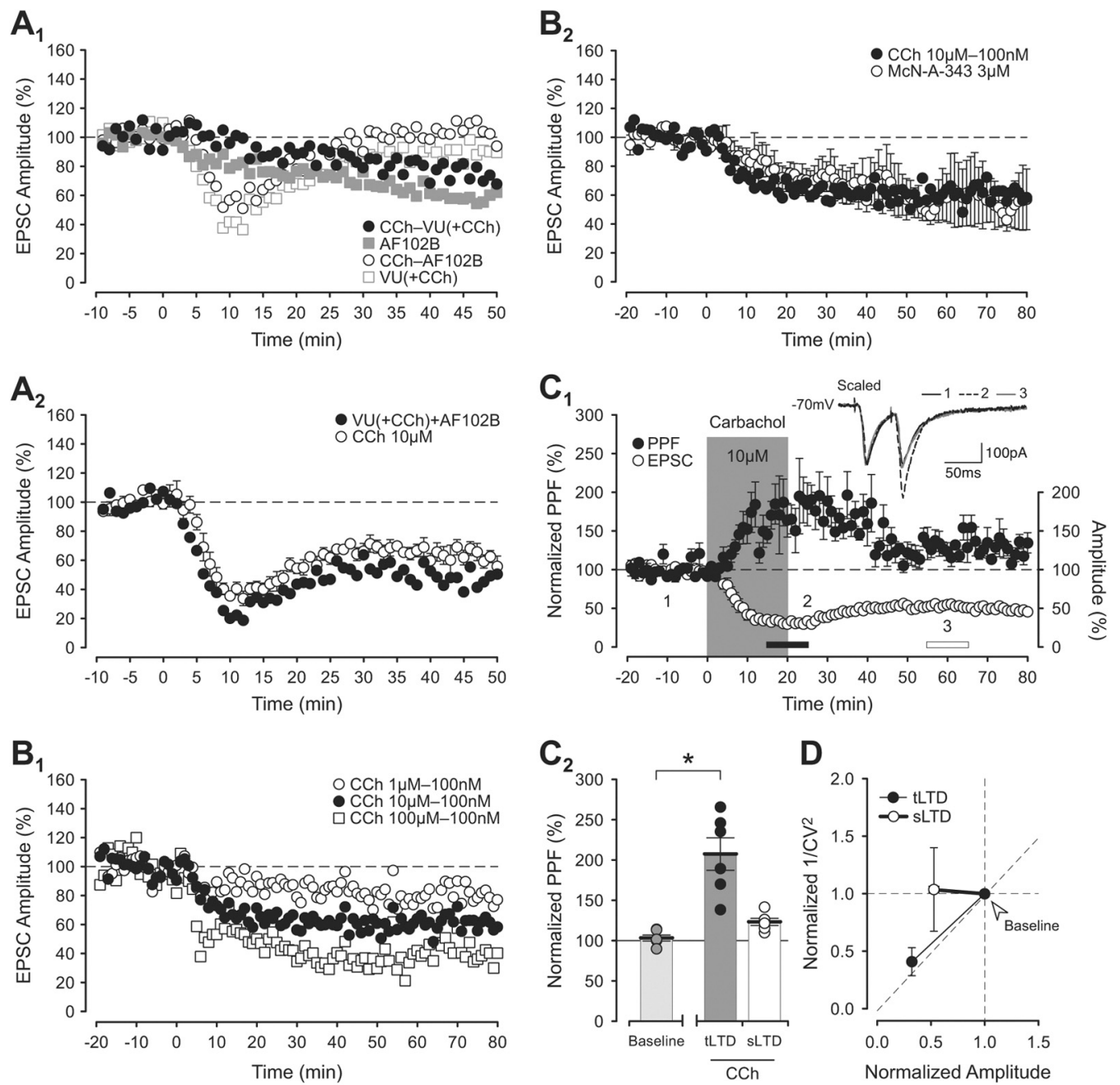

Figure 5. The carbachol-mediated sLTD of EPSCs depends on activation of postsynaptic $M_{1}$ receptors, whereas tLTD is mediated presynaptically by a reduction in glutamate release. $A$, Results for experiments using selective $M_{1}$ agonists and antagonists provide clues to a possible mechanistic dissociation between LLTD and SLTD. Subtracting the data set for experiments using the $M_{1}$ antagonist VU0255035 ( + carbachol) (see Fig. 3C $C_{2}$ ) from those during which carbachol was applied alone produces a new data set that closely resembles the results obtained with the $\mathrm{M}_{1}$ agonist AF102B alone $\left[A_{1} ; C C h\right.$ minus VU $(+C C h)$, filled circles; $A F 102 B$, filled squares]. Note, error bars from original data sets used for comparison have been removed for clarity. Similarly, subtracting the AF102B data set (see Fig. $4 A_{2}$ ) from carbachol control data produces results which contain only a tLTD phase with no SLTD, thereby resembling data obtained with VU0255035(+ carbachol) $\left[A_{2} ;(C h\right.$ minus AF102B, open circles; $\mathrm{VU}(+\mathrm{CCh})$, open squares]. Interestingly, combining the results for experiments with AF102B and VU0255035( + carbachol) produces a data set that precisely mirrors results obtained during control experiments when carbachol was applied alone $\left(A_{2}\right)$, suggesting that the SLTD of EPSCs is mediated solely by activation of $M_{1}$ receptors. $B$, The onset of sLTD is observed more clearly when the effects of tLTD are subtracted. Bath application of $100 \mathrm{~nm}$ carbachol typically induces tLTD of EPSCs with no lasting sLTD of transmission (see Fig. 1D 1 , open circles). As a result, the $100 \mathrm{~nm}$ data can be subtracted from the results for 1,10 , and $100 \mu \mathrm{m}$ carbachol to better visualize the onset of SLTD. The results are shown in $\boldsymbol{B}_{1}$ for 1 (open circles), 10 (filled circles), and 100 (open squares) $\mu$ m carbachol. Interestingly, the data obtained with McN-A-343 (see Fig. $4 A_{1}$ ) are nearly identical to the $10 \mu$ m carbachol data that has the tLTD component subtracted ( $\boldsymbol{B}_{2}$ ). C, The carbachol-mediated depression of EPSCS is expressed, in part, by a reduction in the release probability of glutamate. There was a significant increase in paired-pulse facilitation that was time-locked to the tLTD of EPSCs induced by $10 \mu \mathrm{M} C \mathrm{Ch}\left(\boldsymbol{C}_{i} ;\right.$ PPF, filled circles; EPSC amplitude, open circles). Interestingly, paired-pulse ratios returned to baseline levels during sLTD (summarized in $\left.\boldsymbol{C}_{2} ;{ }^{*} p<0.05\right)$. D. Bath application of carbachol also increased response-to-response variability during tLTD as indicated by a reduction in the coefficient of variation. Normalized $1 /\left(V^{2}\right.$ was computed for 10 min epochs of stable EPSCs recorded during the peak of tLTD ( $\boldsymbol{C}_{1}$, latency indicated by the black bar) and during SLTD ( $\boldsymbol{C}_{\boldsymbol{1}}$, white bar) and expressed as a ratio of the baseline for plotting. Similar to findings for paired-pulse facilitation, the reduction in $1 / C V^{2}$ observed during tLTD was transient (filled circles) and response-to-response variability returned to baseline levels during SLTD (open circles).

mediated solely by activation of $\mathrm{M}_{1}$ receptors. Indeed, it is possible to generate completely new sets of data from carbachol control experiments that closely resemble results obtained for separate experiments using either the $\mathrm{M}_{1}$ agonist $\mathrm{AF} 102 \mathrm{~B}$ or the $\mathrm{M}_{1}$ antagonist VU0255035. As shown in Figure $5 A_{1}$, subtracting the data set obtained during the coapplication of VU0255035 and carbachol from the time-matched control experiment in which carbachol was applied alone produces a new data set that closely resembles the results obtained from Figure $4 A_{2}$ when the $M_{1}$ agonist AF102B was applied alone (Fig. $5 A_{1}$, filled circles vs filled squares). Similar to the AF102B data set, the results from this subtraction lack an initial tLTD phase and only show a slow-onset
sLTD phase. In contrast, subtracting the AF102B data set from the carbachol control data set produces results that closely mimic those shown in Figure $3 C_{2}$ during the coapplication of VU0255035 and carbachol (Fig. $5 A_{1}$, open circles vs open squares). The resulting data set contains only a tLTD phase and lacks any sustained depression of responses. In addition, the data generated in Figure $5 A_{2}$ in which the AF102B and VU0255035 + carbachol data sets are combined provide further evidence that tLTD and sLTD are mediated by $\mathrm{M}_{1}$ independent and $\mathrm{M}_{1}$-dependent activation, respectively. In this example, the addition of the two sets of experimental data create a result (Fig. $5 A_{2}$, filled circles) that almost perfectly 
approximates those data obtained during experiments in which carbachol was bath applied alone (Fig. $5 A_{2}$, open circles). Together, these findings offer further support that the sLTD of EPSCs is mediated by activation of $M_{1}$ receptors.

As shown in Figure $1 D_{1}$, bath application of $100 \mathrm{~nm}$ carbachol (open circles) induced tLTD of EPSCs with no sLTD. Thus, subtracting the $100 \mathrm{~nm}$ data set from results obtained for 1,10 , and $100 \mu \mathrm{M}$ carbachol allows sLTD to be visualized with little interference from transient effects of tLTD (Fig. $5 B_{1}$ ). Interestingly, the data obtained with McN-A-343 (from Fig. $4 A_{1}$ ) are nearly identical to the $10 \mu \mathrm{M}$ carbachol data that has the tLTD component subtracted (see Fig. $5 B_{2}$ ), and this further suggests that the sLTD of EPSCs induced by carbachol is mediated, primarily, by activation of $\mathrm{M}_{1}$ mAChRs.

In additional experiments, paired-pulse tests were used to determine whether carbachol depresses EPSCs through a presynaptic or postsynaptic mechanism. Pairs of stimulation pulses separated by an interval of $50 \mathrm{~ms}$ were delivered before and after 20 min bath application of $10 \mu \mathrm{M}$ carbachol (Fig. $5 C_{1} ; n=6$ ). Paired-pulse facilitation data in Figure $5 C_{1}$ is shown superimposed together with the EPSC amplitude data from Figure $1 D_{1}$. Note that the ILTD of EPSCs induced by carbachol is time-locked to a significant increase in paired-pulse facilitation. Although paired-pulse facilitation increased significantly to $207.2 \pm 20.1 \%$ of baseline levels following application of carbachol (Fig. $5 C_{2}$; $F_{(2,9)}=13.31, p<0.01$; Bonferroni, $\left.p<0.01\right)$, the increase was only transient, and the amount of facilitation returned to baseline levels by the end of the experiment (to $123.2 \pm 4.4 \%$ of baseline; Bonferroni, $p=0.16$ ). These data suggest that the tLTD of EPSCs is mediated presynaptically by a reduction in glutamate release. In addition, response-to-response variability in the amplitude of EPSCs increased during tLTD, and this is reflected by a reduction in normalized $1 / C V^{2}$ to $0.41 \pm 0.12$ of baseline computed for a 10 min epoch of stable EPSCs recorded during the peak of tLTD (Fig. $5 D$, filled circles; $n=10$ ). Similar to findings for paired-pulse facilitation, the reduction in $1 / C V^{2}$ observed during tLTD was transient and response-to-response variability returned to baseline levels during SLTD (to $1.04 \pm 0.36$; Fig. $5 D$, open circles). Together, these data suggest that the tLTD of EPSCs is mediated presynaptically by a temporary reduction in glutamate release and that the SLTD of synaptic responses is not associated with a significant change in the release probability of neurotransmitter.

\section{The role of NMDARs, mGluRs, postsynaptic $\mathrm{Ca}^{2+}$ signaling, and PKC in carbachol-mediated LTD}

Activation of NMDA receptors and mGluRs is important in the induction of a variety of forms of synaptic plasticity. Bath application of carbachol in the presence of the NMDAR antagonist AP5 $(50 \mu \mathrm{M})$ resulted in tLTD and sLTD of EPSCs $(19.4 \pm 7.5 \%$ and $61.0 \pm 9.2 \%$ of baseline, respectively; Fig. $6 \mathrm{~A}$, filled circles; $n=4)$ that was not significantly different from control LTD induced by carbachol alone (tLTD, $F_{(2,15)}=61.84, p<0.0001$, Bonferroni, $p=0.57$; sLTD, $F_{(2,15)}=13.82, p<0.001$, Bonferroni, $p=0.86$ ). In addition, carbachol-mediated LTD was unaffected by application of the broad spectrum mGluR antagonist LY341495 (100 $\mu$ m; Fig. 6B, filled circles; $n=5$; tLTD, $24.4 \pm$ $3.2 \%$ of baseline; $F_{(2,19)}=151.7, p<0.0001$, Bonferroni, $p=$ 0.126 ; sLTD, $62.3 \pm 6.7 \%$ of baseline; $F_{(2,19)}=36.51, p<0.0001$, Bonferroni, $p=1.00$ ). To investigate whether an increase in postsynaptic calcium was required for carbachol-mediated LTD, experiments were conducted in which the recording pipette contained 10 mM BAPTA $(n=8)$; this manipulation had no effect on the magnitude of carbachol-LTD (responses were reduced to $29.8 \pm 2.4 \%$ and $66.9 \pm 7.4 \%$ of baseline for tLTD and sLTD, respectively; Fig. $6 C$; $\operatorname{tLTD}, F_{(2,22)}=170.4, p<0.0001$, Bonferroni, $p=0.54$; sLTD, $F_{(2,22)}=20.29, p<0.0001$, Bonferroni, $p=0.63$ ). It has previously been reported that nitric oxide is required for carbachol-LTD in prefrontal cortex (Huang and Hsu, 2010). However, the nitric oxide synthase inhibitor L-NAME $(50 \mu \mathrm{M})$ had no effect on the tLTD and SLTD induced by $10 \mu \mathrm{M}$ carbachol (EPSCs reduced to $26.6 \pm 2.4$ and $59.4 \pm$ $3.0 \%$ of baseline, respectively; Fig. $6 D ; n=6$; tLTD, $F_{(2,20)}=$ $165.9, p<0.0001$, Bonferroni, $p=0.20$; sLTD, $F_{(2,20)}=61.42$, $p<0.0001$, Bonferroni, $p=0.62$ ). Muscarinic receptors are known to trigger metabotropic cascades that lead to the activation of PKC. To examine the role of PKC in carbachol-mediated LTD, carbachol was bath applied in the presence of the extracellularly applied inhibitor Ro-31-8220 (2.5 $\mu \mathrm{M}$; Fig. $\left.6 E_{1} ; n=5\right)$ or the intracellularly applied inhibitors PKC (19-36) (10 $\mu \mathrm{M}$; Fig. $\left.6 E_{2} ; n=5\right)$ or Ro-32-0432 (10 $\mu \mathrm{M} ; n=5$; data not shown). Under all three of these conditions tLTD was unaffected (Ro-31-8220, $45.9 \pm 8.1 \%$ of baseline, $F_{(2,19)}=67.19, p<0.0001$, Bonferroni, $p=0.54$; PKC (19-36), $26.0 \pm 3.2 \%$ of baseline, $F_{(2,19)}=148.3$, $p<0.0001$, Bonferroni, $p=0.22$; Ro-32-0432, $42.0 \pm 9.1 \%$ of baseline, $F_{(2,19)}=62.07, p<0.0001$, Bonferroni, $\left.p=1.00\right)$. In contrast sLTD was blocked. Responses during SLTD were $99.4 \pm$ $4.7 \%$ of baseline in the presence of Ro-31-8220 (Fig. $6 E_{1}$ ), $88.9 \pm$ $4.4 \%$ of baseline in cells loaded with PKC (19-36) (Fig. $\left.6 E_{2}\right)$, and $94.2 \pm 2.2 \%$ of baseline in Ro-32-0432 (data not shown). Each of these conditions were significantly different to sLTD induced by carbachol alone (Ro-31-8220; Fig. $6 E_{1} ; F_{(2,19)}=39.66, p<0.0001$, Bonferroni, $p<0.0001$; PKC (19-36); Fig. $6 E_{2}, F_{(2,19)}=36.77, p<$ 0.0001, Bonferroni, $p<0.001$; Ro-32-0432, $F_{(2,19)}=46.84, p<$ 0.0001 , Bonferroni, $p<0.0001$ ). These results show that LTD induced by stimulation of acetylcholine receptors by carbachol does not require additional activation of NMDA or mGluRs or increases in intracellular calcium or the second messenger nitric oxide. However, there is a requirement for activation of PKC in carbacholmediated sLTD but not tLTD in MPFC.

\section{Activation of $M_{1}$ receptors facilitates induction of activity-dependent LTD}

We next investigated whether activity-dependent LTD can be induced by synaptic stimulation in prefrontal cortex and whether such activity-dependent LTD shares properties with carbacholmediated LTD. LTD in many brain preparations, especially in adult cortex, is induced by delivery of paired-pulse low-frequency stimulation (PP-LFS) (Kemp and Bashir, 2001; Caruana et al., 2007). To begin this series of experiments we investigated the lower threshold requirements for LTD. We first delivered 300 paired stimuli $(50 \mathrm{~ms}$ interpulse interval; $1 \mathrm{~s}$ between consecutive pairs). However, this protocol did not result in LTD (Fig. $7 A ; n=6$ ). Responses remained stable at $96.9 \pm 8.9 \%$ of baseline levels and did not differ significantly from responses evoked in a separate control pathway that did not receive $\operatorname{LFS}\left(t_{(5)}=0.48, p=0.65\right)$.

To investigate whether insufficient acetylcholine levels are a limiting factor for LTD induction, we delivered 300 PP-LFS, but in the presence of the acetylcholinesterase inhibitors physostigmine $\left(2 \mu \mathrm{M}\right.$; Fig. $\left.7 B_{1} ; n=6\right)$ or BW $284 \mathrm{c} 51\left(200 \mathrm{nM}\right.$; Fig. $7 B_{2} ; n=$ 4) to increase levels of acetylcholine in the mPFC. Under either of these conditions 300 PP-LFS resulted in significant and robust LTD. EPSCs were reduced to $63.1 \pm 8.5 \%$ or $50.4 \pm 5.9 \%$ of baseline levels for physostigmine or BW 284c51, respectively, and EPSCs were significantly depressed relative to control responses (physostigmine, $t_{(5)}=3.29, p<0.05$; BW 284c51, $t_{(3)}=7.78, p<$ 
A

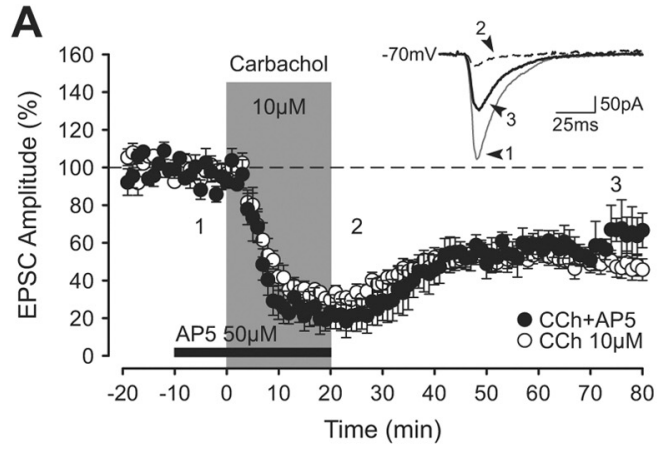

B
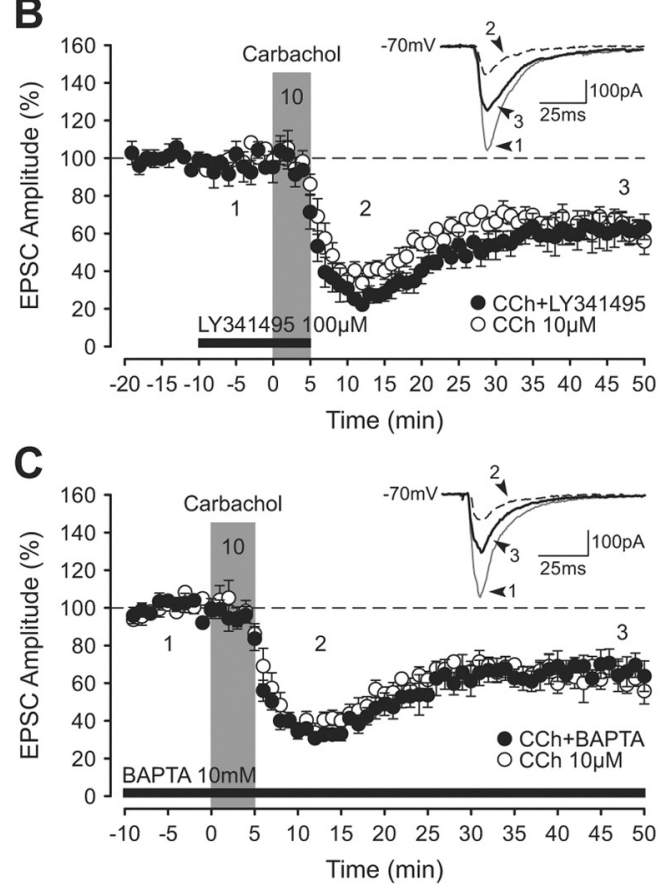
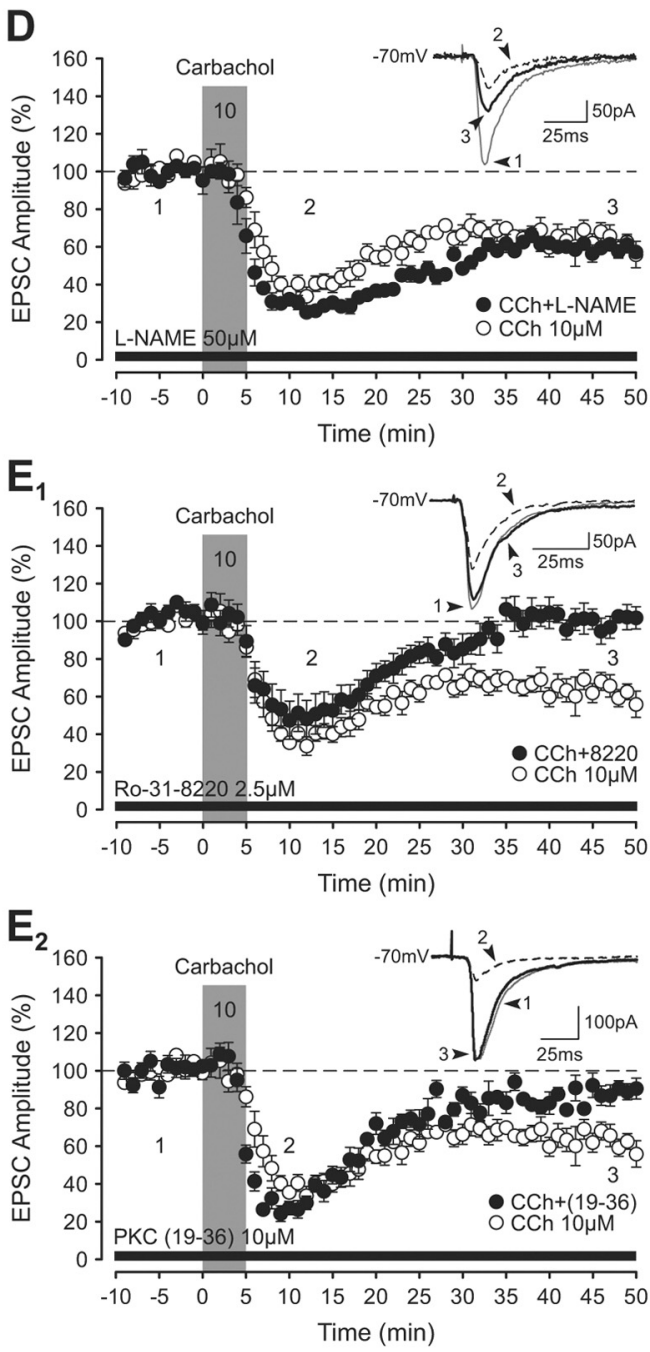

Figure 6. Induction of carbachol-LTD does not require activation of NMDA receptors, mGluRs, or a rise in postsynaptic calcium, but depends critically on activity of protein kinase C. Coapplication of either the NMDA receptor antagonist AP5 $(\boldsymbol{A} ; 50 \mu \mathrm{M})$ or the mGluR antagonist LY341495 (B; $100 \mu \mathrm{m}$ which blocks group I, II, and III mGluRs) does not prevent tLTD or sLTD induced by $10 \mu \mathrm{M}$ carbachol. In addition, loading cells with the calcium chelator BAPTA $(\boldsymbol{C} ; 10 \mathrm{mM})$ or continuous application of the nitric oxide synthase inhibitor L-NAME (D; $50 \mu \mathrm{M})$ has no effect on tLTD and sLTD induced by carbachol in the prelimbic region. $E$, The sustained depression of EPSCs requires activity of PKC. Continuous perfusion of the PKC inhibitor Ro-31-8220 (2.5 $\mu \mathrm{M})$ blocks the expression of sLTD, but not tLTD, induced by $10 \mu \mathrm{m}$ carbachol $\left(\boldsymbol{E}_{1}\right)$. Similarly, loading cells with the PKC inhibitor PKC (19-36) (10 $\left.\mu \mathrm{M}\right)$ also prevents the expression of sLTD and has no effect on the transient suppression of synaptic responses $\left(\boldsymbol{E}_{2}\right)$.

0.01). These data suggest that the levels of acetylcholine are an important factor in LTD induction and further suggest that 300 PP-LFS alone does not raise acetylcholine levels sufficiently to induce LTD.

Our previous data (Figs. 4, 5) suggests that $M_{1}$ receptors are important for induction of the sustained phase of LTD. To examine whether increasing $M_{1}$ receptor activation specifically, as opposed to raising basal acetylcholine levels, would convert the 300 PP-LFS subthreshold stimulation into a suprathreshold stimulation protocol, we delivered 300 PP-LFS in the presence of the $\mathrm{M}_{1}$-positive allosteric modulator BQCA $\left(10 \mu \mathrm{M}\right.$; Fig. $\left.7 C_{1} ; n=5\right)$. This pairing produced robust LTD (to $53.4 \pm 3.3 \%$ of baseline; $\left.t_{(4)}=8.51, p<0.001\right)$. Furthermore, LTD induced under these conditions was prevented by the muscarinic antagonist scopolamine (10 $\mu \mathrm{M}$; Fig. $\left.7 C_{2} ; n=5\right)$. Responses remained stable at $89.3 \pm 7.2 \%$ of baseline and did not differ significantly from control EPSCs (control responses were $89.1 \pm 5.2 \%$ of baseline during the last $5 \mathrm{~min}$ of the experiment, $t_{(4)}=0.03, p=0.98$ ). These results suggest that 300 PP-LFS results in insufficient activation of $M_{1}$ receptors by endogenous acetylcholine to induce LTD. However, manipulations that increase acetylcholine levels or $\mathrm{M}_{1}$ "potency" during such subthreshold stimulation can result in the induction of LTD.

In the next series of experiments we used an alternative stimulation protocol that was also subthreshold for LTD induction. Thus, we found that 450 single-pulses delivered at a frequency of $1 \mathrm{~Hz}$ did not result in LTD (Fig. $8 A_{1} ; n=5$ ). Responses remained stable at $94.5 \pm 3.2 \%$ of baseline levels and did not differ significantly from responses evoked in the control pathway (Fig. $8 \mathrm{~A}_{2}$; $\left.t_{(4)}=0.45, p=0.67\right)$. However, 450 stimuli delivered in the presence of the acetylcholinesterase inhibitor physostigmine (2 $\mu \mathrm{M}$ ) did result in LTD (Fig. $8 B_{1} ; n=5$ ). The amplitude of EPSCs recorded during the last $5 \mathrm{~min}$ of the experiment were reduced to $56.4 \pm 4.2 \%$ of baseline, and responses were significantly depressed relative to the control input that did not receive LFS (Fig. $\left.8 B_{2} ; t_{(4)}=6.32, p<0.01\right)$. Furthermore, 450 stimuli at $1 \mathrm{~Hz}$, delivered in the presence of $10 \mu \mathrm{M}$ BQCA, also produced robust LTD (Fig. $8 C_{1} ; n=5$ ). Under these conditions, responses were reduced to $42.6 \pm 5.3 \%$ of baseline that were significantly depressed relative to control responses (Fig. $8 C_{2} ; t_{(4)}=8.30, p<$ 0.01 ). Therefore, taken together, our results show that two differ- 
A

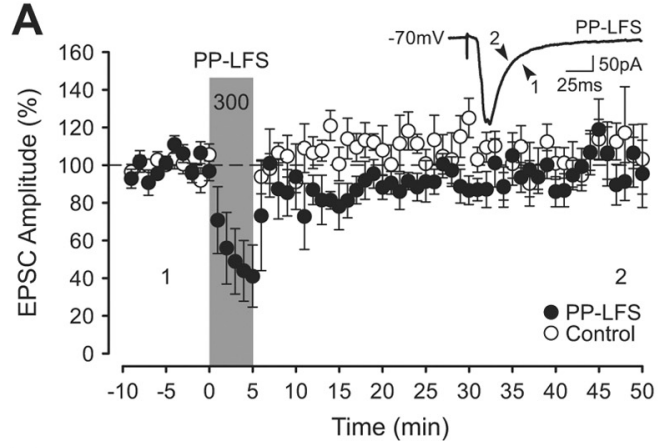

$\mathrm{B}_{1}$

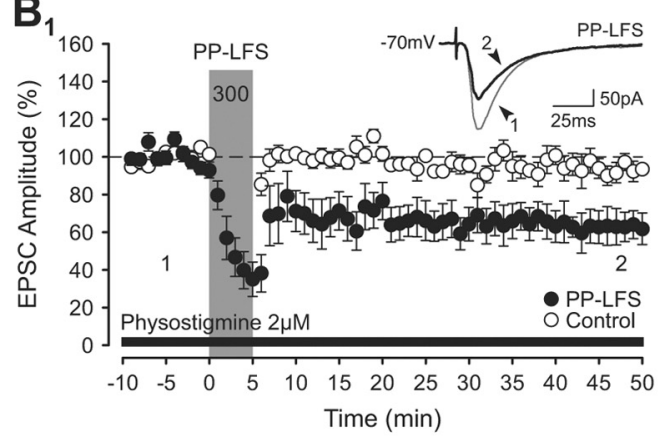

$\mathrm{B}_{2}$

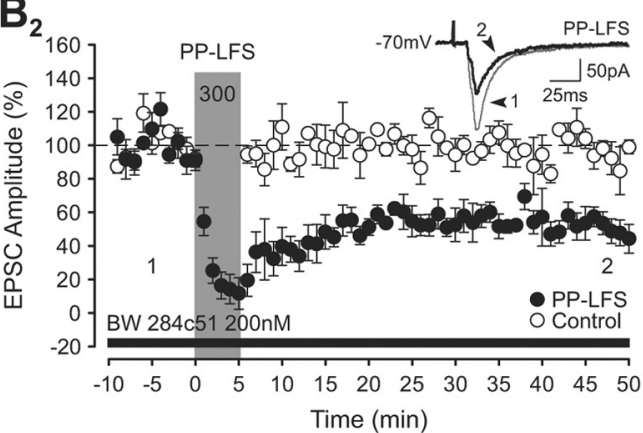

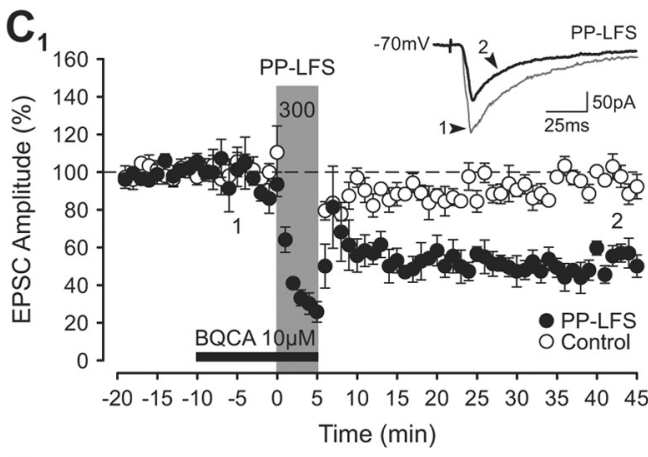

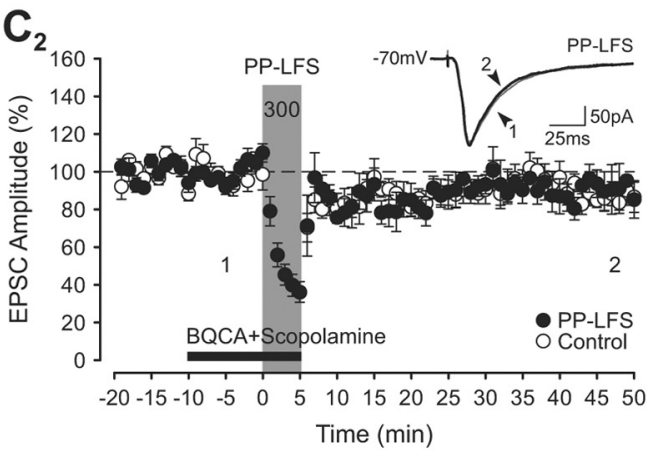

D

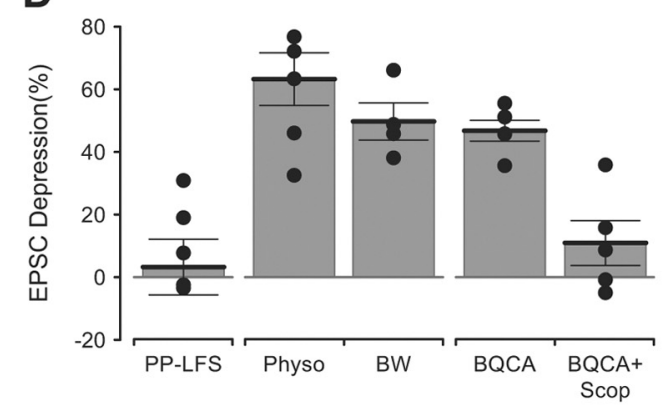

Figure 7. Enhancing either cholinergic tone or the sensitivity of $\mathrm{M}_{1}$ receptors converts a subthreshold LFS protocol into one which induces LTD. $A$, Delivery of 300 pairs of stimulation pulses ( 50 ms interpulse interval) at a frequency of $1 \mathrm{~Hz}$ (PP-LFS; gray bar) to one input (either the dorsal or ventral input; selected at random) fails to induce LTD in the mPFC (filled circles; PP-LFS). The second input (open circles; Control) did not receive LFS in this and subsequent figures. $\boldsymbol{B}$, Enhancing cholinergic tone by blocking activity of acetylcholinesterases facilitates induction of LTD following delivery of subthreshold LFS. Continuous perfusion of the acetylcholinesterase inhibitors physostigmine $\left(\boldsymbol{B}_{i} ; 2 \mu \mathrm{M}\right)$ or BW $284 C 51\left(\boldsymbol{B}_{2} ; 200 \mathrm{nM}\right)$ converts the subthreshold 300 PP-LFS protocol into one which induces $L T D$. C, Enhancing the sensitivity of $M_{1}$ receptors to acetylcholine also facilitates induction of LTD induced by subthreshold LFS. Pairing bath application of BQCA (10 $\left.\mu \mathrm{M}\right)$ with the 300 PP-LFS protocol induced LTD in the prelimbic region $\left(\boldsymbol{C}_{1}\right)$. Coapplication of scopolamine $(10 \mu \mathrm{M})$ with BQCA during PP-LFS blocks induction of LTD $\left(\boldsymbol{C}_{2}\right)$. D, Summary histogram comparing results obtained during delivery of 300 PP-LFS alone or together with treatments to enhance $M_{1}$ receptor activation.

ent subthreshold induction paradigms can become suprathreshold for LTD induction simply by increasing cholinergic tone and/or $M_{1}$ muscarinic receptor activation.

\section{A novel form of activity-dependent LTD that relies on endogenous acetylcholine receptor activation}

We next examined whether increasing the duration of the subthreshold stimulation protocol would result in LTD without the need for pharmacological manipulation of muscarinic receptors. Therefore, we modified the induction protocol and increased the number of pulse-pairs from 300 to 450 during $1 \mathrm{~Hz}$ LFS. This protocol did, indeed, result in robust LTD (Fig. $9 A ; n=5$ ). Delivery of this LFS protocol reduced responses to $61.2 \pm 5.6 \%$ of baseline levels and induced significant LTD of EPSCs relative to responses in the control pathway that did not receive LFS $t_{(4)}=$ $3.22, p<0.05)$. In contrast, delivery of the same LFS stimulation protocol within layer $\mathrm{V}$ did not induce significant LTD; responses remained stable at $83.6 \pm 6.9 \%$ of baseline and did not differ significantly from controls $\left(t_{(5)}=2.15, p=0.09\right.$; data not shown). Interestingly, LTD induced by 450 PP-LFS was not blocked by loading cells with the NMDAR antagonist MK-801 (3 $\mathrm{mM}$, Fig. $9 B ; n=5$ ); responses were reduced to $59.7 \pm 3.5 \%$ of baseline and were significantly depressed relative to controls $\left(t_{(4)}=\right.$ $11.81, p<0.001)$.

In line with the signaling cascades found for carbachol-LTD, the activity-dependent LTD induced by 450 PP-LFS was not blocked by loading cells with BAPTA ( $10 \mathrm{~mm}$; Fig. $9 C$; $n=5)$ but was blocked by inhibition of PKC (Fig. $9 D ; n=6$ ). Responses remained stable at $84.5 \pm 11.8 \%$ of baseline during the pairing of Ro-31-8220 (2.5 $\mu \mathrm{M})$ with PP-LFS, and EPSCs did not differ significantly from control responses $\left(t_{(5)}=1.530, p=0.19\right)$. LTD was also blocked by the muscarinic receptor antagonist scopolamine (10 $\mu \mathrm{M}$; Fig. 9E; $n=5)$. Responses remained stable at $83.8 \pm 7.9 \%$ of baseline following the pairing of PP-LFS with scopolamine, and EPSCs were not significantly depressed relative to controls (control EPSCs were $89.3 \pm 4.7 \%$ of baseline during the last 5 min of the experiment, $t_{(4)}=1.46, p=0.22$ ). Furthermore, this form of activity-dependent LTD in the prelim- 

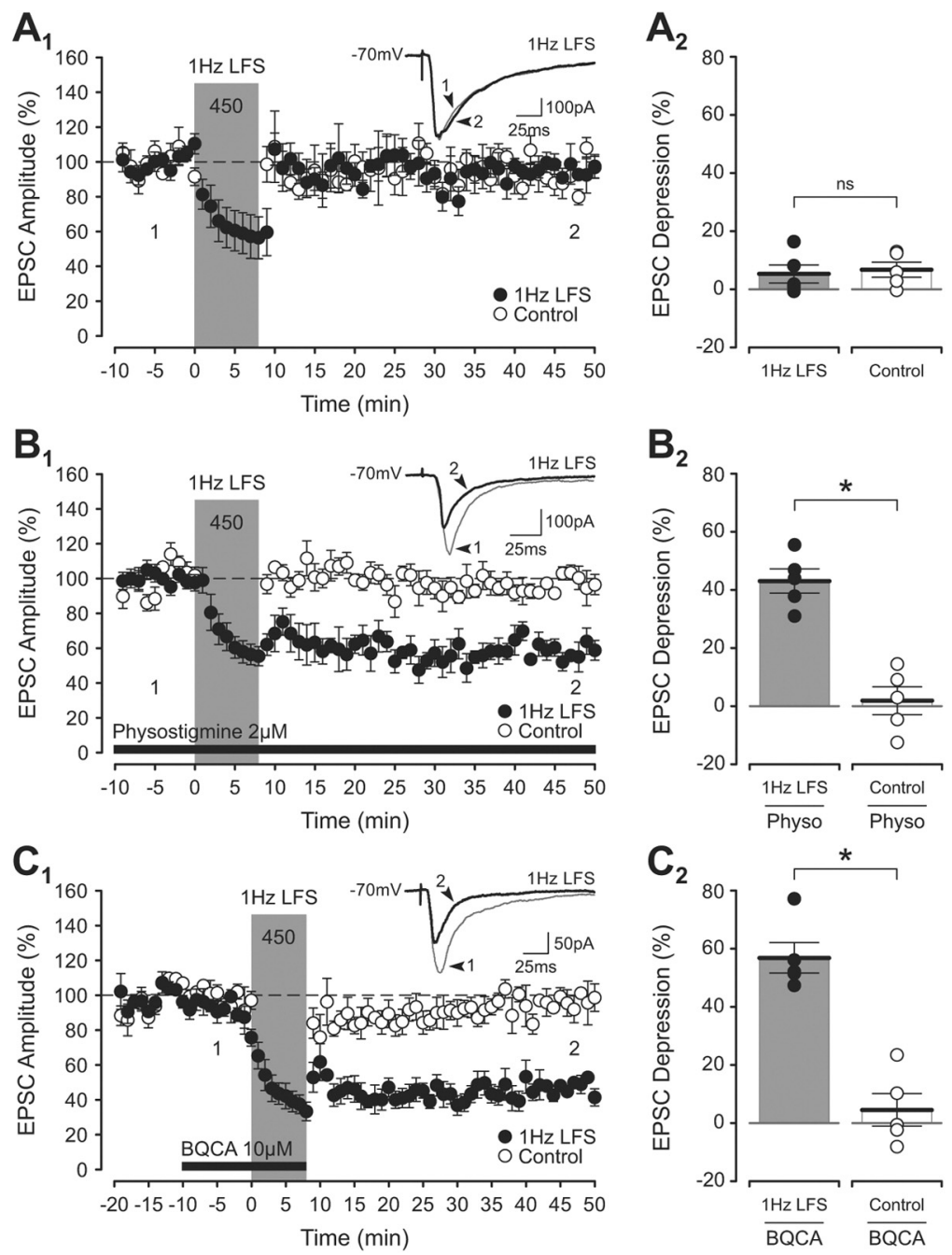

Figure 8. An alternative subthreshold LFS protocol can be made to induce LTD when paired with bath application of physostigmine or BQCA. The delivery of 450 single-pulses to the superficial layers at $1 \mathrm{~Hz}$ typically fails to induce LTD in the prelimbic region $\left(\boldsymbol{A}_{\boldsymbol{1}}\right.$, filled circles; $\boldsymbol{A}_{2}$, ns, not significant). However, continuous application of the acetylcholinesterase inhibitor physostigmine (2 $\mu \mathrm{M})$ converts the subthreshold LFS protocol into one which induces significant LTD ( $\boldsymbol{B}_{\boldsymbol{1}}$, filled circles; $\boldsymbol{B}_{\mathbf{2}},{ }^{*} \boldsymbol{p}<0.05$ ). In addition, increasing the sensitivity of $M_{1}$ receptors to acetylcholine with BQCA also facilitates induction of LTD in response to subthreshold $\operatorname{LFS}\left(\boldsymbol{C}_{1}\right.$, filled circles; $\left.\boldsymbol{C}_{2},{ }^{*} p<0.05\right)$.

bic region is $M_{1}$ receptor-dependent: application of the selective $M_{1}$ receptor antagonist VU0255035 $(10 \mu \mathrm{M})$ blocked induction (Fig. 9F; $n=6)$. Responses did not differ significantly from EPSCs evoked in the unconditioned control pathway $\left(t_{(5)}=2.25, p<0.05\right)$. Under these conditions, therefore, LTD relies on acetylcholine and PKC activation and parallels the findings that carbachol-mediated LTD relies on PKC but not postsynaptic increases in calcium. These results suggest that LTD can be induced provided that sufficient release of acetylcholine and activation of $M_{1}$ receptors is achieved. In addition, these results also indicate that with the stimulation required to induce acetylcholine-mediated LTD, there is no requirement for activation of NMDA receptors.

\section{Discussion}

Glutamate receptors are involved in the induction of synaptic plasticity in different brain regions (Bliss and Collingridge, 1993; Bear and Abraham, 1996; Bilkey, 1996; McCaffery et al., 1999; Ziakopoulos et al., 1999; Cho et al., 2000), but it is unclear how other neurotransmitter systems modulate synaptic plasticity in the CNS. We now demonstrate that pharmacological activation of acetylcholine receptors induces LTD in the mPFC. Crucially, we demonstrate induction of activity-dependent LTD that relies solely on endogenous acetylcholine. This form of synaptic plasticity may underlie the $\mathrm{mAChR}$ role in prefrontal cortexdependent learning and memory (Barker and Warburton, 2009). Moreover, deficits in associative memory in Alzheimer's dementia may result from impaired synaptic plasticity in $\mathrm{mPFC}$ following loss of cholinergic innervation.

\section{Agonist-induced LTD}

The induction of LTD by the acetylcholine agonist carbachol was not prevented by NMDAR or mGluR antagonism, indicating that these receptors are not required for carbachol-mediated LTD. Furthermore, carbachol-LTD was induced in the absence of synaptic stimulation. Thus, acute activation of mAChRs alone produces a long-lasting depression of synaptic transmission in mPFC (Wang and Yuan, 2009; Huang and $\mathrm{Hsu}, 2010)$ and in other cortical regions, including perirhinal (Massey et al., 2001) and visual (McCoy and McMahon, 2007) cortices.

Carbachol-LTD was reduced by inhibition of $M_{1}$ receptors by pirenzepine or VU0255035 and mimicked by the $M_{1}$ agonists $\mathrm{McN}-\mathrm{A}-343$ or AF102B. Interestingly, the $M_{1}$ agonists produced a slowonset depression without significant transient LTD. Furthermore, the presence of the $M_{1}$ antagonists prevented sustained LTD and had little effect on transient LTD. In other experiments, LTD was induced by a subthreshold concentration of carbachol in the presence of the $\mathrm{M}_{1}$ potentiator BQCA that increases affinity of the receptor to $\mathrm{M}_{1}$ ligands ( $\mathrm{Ma}$ et al., 2009; Shirey et al., 2009). Together, the results with pirenzepine, VU0255035, MCN-A-343, AF102B, and BQCA suggest that $M_{1}$ receptor activation underlies induction of sustained LTD in mPFC. In further support of the hypothesis that the transient and sustained phases of carbachol-LTD are mediated by different mechanisms we found that the early, but not late, stages of depression were associated with changes in presynaptic glutamate release, as indicated by changes in paired-pulse facilitation and coefficient of variation. This is in keeping with previous reports (McCoy and McMahon, 2007; Huang and Hsu, 2010). Our results also showed that EPSC decay kinetics were stable during experiments with carbachol. Thus, while sLTD is most likely a postsynaptic phenomenon, it is unlikely that the expression of carbachol-LTD is associated with changes in the subunit composition of AMPA receptors.

Muscarinic $M_{1}$ receptors couple to phospholipase $C$, which results in the production of diacylglycerol and an upregulation of PKC (Levey, 1996; Eglen, 2006). In keeping with this (Huang and Hsu, 2010) we found that inhibition of PKC prevented carbachol-LTD. Interestingly, bath applied or postsynap- 

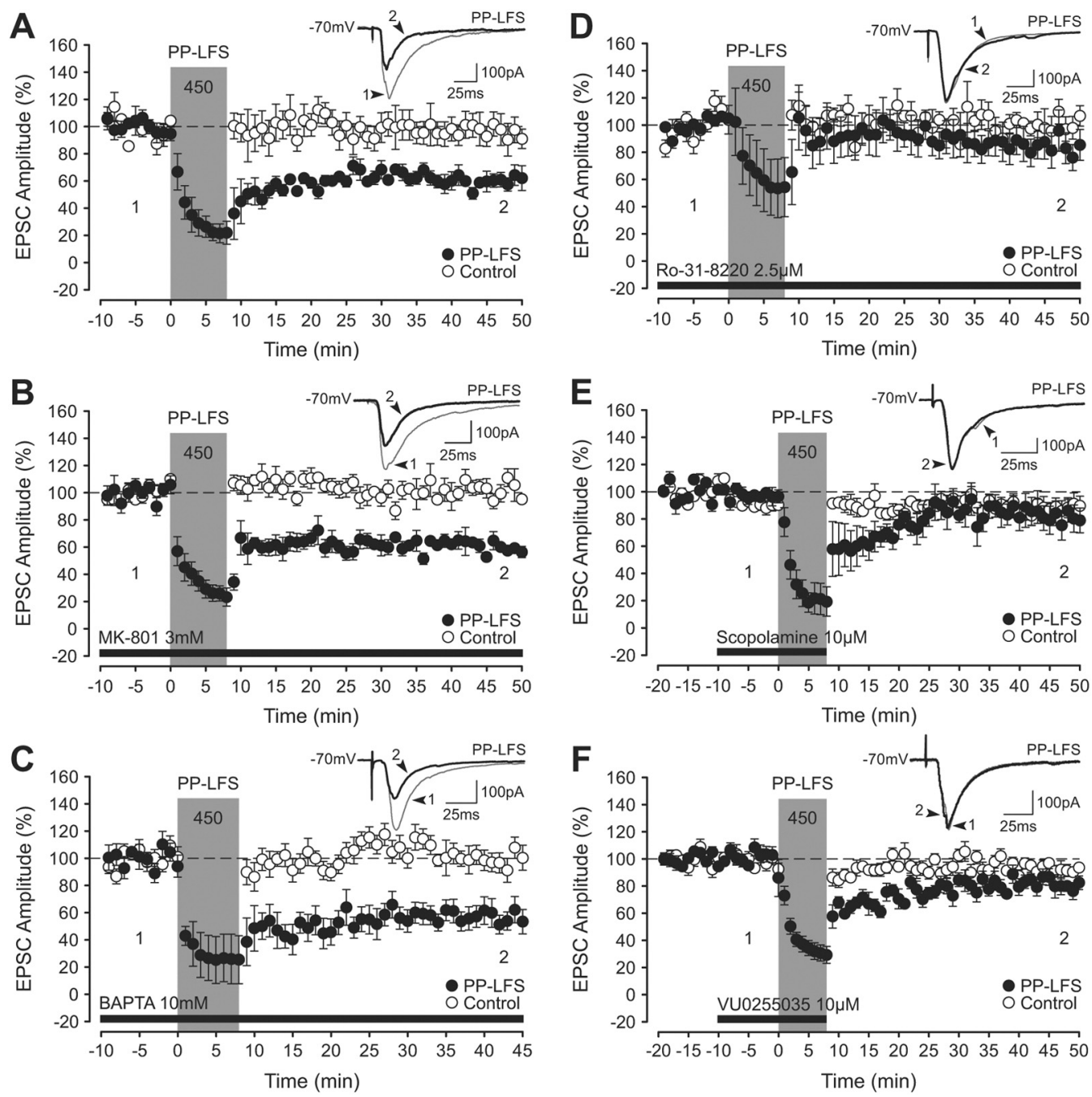

Figure 9. Increasing the number of stimulation pulse-pairs from 300 to 450 during PP-LFS enhances release of acetylcholine to levels sufficient to induce $M_{1}$ receptor-dependent LTD in the prelimbic region. $A$, The delivery of 450 pairs of stimulation pulses ( $50 \mathrm{~ms}$ interpulse interval) at a frequency of $1 \mathrm{~Hz}$ induces LTD in the mPFC. Induction of this LTD is not blocked by loading cells with the NMDA receptor channel blocker MK-801 (3 mм; $\boldsymbol{B}$ ) or the calcium chelator BAPTA (10 mм; C). Interestingly, however, constant perfusion with the PKC inhibitor Ro-31-8220 (2.5 $\mu \mathrm{m})$ blocked induction of LTD (D). E, The depression of EPSCs induced by 450 PP-LFS was blocked by scopolamine (10 $\mu \mathrm{m})$, indicating a critical role for muscarinic receptors. Additionally, induction of LTD was blocked by VU0255035 $(10 \mu \mathrm{M} ; \boldsymbol{F})$ suggesting that this form of activity-dependent depression is mediated, specifically, by activation of $\mathrm{M}_{1}$ receptors. Note that the pharmacology for this form of activity-dependent LTD mirrors that observed for experiments assessing the effects of carbachol alone on basal synaptic transmission in the prelimbic region.

tically delivered PKC inhibitors prevented SLTD, with no effect on tLTD. This suggests that $\mathrm{M}_{1}$ receptors couple to PKC to induce sLTD but that an $\mathrm{M}_{1}$ and PKC-independent mechanism is responsible for tLTD. Activation of phospholipase $\mathrm{C}$ can also increase inositol triphosphate turnover and, hence, release calcium from intracellular stores. However, in contrast to Huang and Hsu (2010) and McCoy et al. (2007), we found no evidence that an increase in intracellular calcium or nitric oxide (Huang and Hsu, 2010) is required for carbachol-LTD. We reported previously, however, that application of carbachol induces LTD in perirhinal cortex that depends on calcium release from intracellular stores (Massey et al., 2001). The reasons for such marked discrepancies between studies are not clear, but it is likely that under different conditions (Huang and Hsu, 2010) and in different brain regions (Kirkwood et al., 1999; Massey et al., 2001; McCoy and McMahon, 2007), different intracellular cascades mediate acetylcholine-induced synaptic plasticity.

\section{Activity-dependent LTD}

Interestingly, we found that weak stimulation protocols (300 stimulus-pairs at $1 \mathrm{~Hz}$ or 450 single-pulses at $1 \mathrm{~Hz}$ ) subthreshold for inducing LTD can induce a lasting depression if levels of acetylcholine are increased by blocking acetylcholinesterase or if delivered with BQCA (Ma et al., 2009; Shirey et al., 2009). This facilitation of activity-dependent LTD parallels results showing that a subthreshold concentration of carbachol induces LTD in the presence of BQCA. The enhancement of LTD by BQCA was blocked by $\mathrm{mAChR}$ antagonism, illustrating that mAChRs are involved in activity-dependent LTD. It has been shown previously that $\mathrm{BQCA}$ enhances $\mathrm{M}_{1}$ receptor-dependent calcium rises in cell lines, muscarinic currents in prefrontal cortex, and c-fos activation in vivo (Ma et al., 2009; Shirey et al., 2009). However, our results are the first to demonstrate a facilitatory role of BQCA in either carbachol-mediated or activity-dependent synaptic plasticity.

To increase the effects of endogenous acetylcholine without pharmacological manipulation we increased the intensity of the stimulus protocol to 450 pulse-pairs (also delivered at $1 \mathrm{~Hz}$ ) and found that this produced robust LTD that was blocked by the mAChR antagonist scopolamine or by the $\mathrm{M}_{1}$-selective antagonist VU0255035. These results suggest that the 450 PP-LFS pro- 
tocol leads to sufficient endogenous acetylcholine release and sufficient activation of $M_{1} m A C h R s$ to induce LTD. In keeping with the intracellular cascades triggered by mAChRs, LTD induced by the 450 PP-LFS protocol was blocked by inhibition of PKC. Moreover, this form of LTD did not require NMDAR activation or an increase in postsynaptic calcium. These results provide further evidence that activation of mAChRs alone, by endogenous acetylcholine, is sufficient to induce LTD. Moreover, these findings provide insight into the potential importance of acetylcholine in LTD in mPFC. The consequences for mPFC circuitry of homosynaptic LTD is not known but several scenarios may exist. Lasting changes in neuronal output related to induction of LTD in MPFC might alter the balance of excitation within and between cortical layers to help encode new information and/or alter mPFC output to modulate behavior. Alternatively, although homosynaptic LTD may help form new associations, large-scale network changes in mPFC might be minimized by homeostatic regulation of plasticity at other synapses.

The relationship between the various forms of LTD that exist in $\mathrm{mPFC}$ and other brain regions is not clear. Previous reports have shown that endogenous acetylcholine can either modulate levels of synaptic plasticity or play a cooperative role with other receptors, such as NMDARs and mGluRs, so that LTD relies on activation of a combination of receptors (Kirkwood et al., 1999; Huber et al., 2001; Huang and Hsu, 2010). In contrast, very few reports show that a muscarinic antagonist alone can block activity-dependent LTD (Bonsi et al., 2008). Our results indicate that activation of mAChRs, by endogenous acetylcholine, is sufficient to induce LTD in mPFC. The reasons why mAChRs alone induce LTD or why, under certain circumstances, recruitment of additional receptors is required, may reflect the intensity of the induction protocols used: intense protocols may produce LTD that relies on several different receptors (Huber et al., 2001; Volk et al., 2007) while modest protocols produce mAChR-dependent LTD (our current results). The relevance of LTD for learning has been described in other studies (Griffiths et al., 2008) and muscarinic-LTD may play a critical role in associative learning in mPFC (Barker and Warburton, 2009). However, it is equally possible that other forms of LTD may be more relevant for different types of learning in other brain regions.

Muscarinic receptors in $\mathrm{MPFC}$ are required to form object-inplace associations (Barker and Warburton, 2009). Additionally, $M_{1}$ receptor knock-out mice show deficits in associative memory that require interactions between cortex and hippocampus (Anagnostaras et al., 2003). It is tempting to speculate that the plasticity induced by the 450 PP-LFS protocol described here might be important in $\mathrm{mPFC}$ associative memory. Forebrain cholinergic inputs to prefrontal cortex are important for associative learning (Ross et al., 2005; Barker and Warburton, 2009) and are tonically active during the awake state. It is possible that tonic cholinergic innervation maintains mPFC networks in a "primed" state so that brief periods of activity related to learning (akin to the subthreshold protocols in our study) are then sufficient to induce LTD. Indeed, lesions of basal forebrain nuclei produce deficits in learning, and a degeneration of cholinergic neurons is associated with age-dependent cognitive decline and Alzheimer's disease (Levey, 1996). Acetylcholinesterase inhibitors are the most widely used medication to treat individuals with Alzheimer's dementia and the enhancement of synaptic plasticity by acetylcholinesterase inhibition that we now demonstrate may be a way in which these drugs provide clinical efficacy. BQCA has been shown to reverse learning deficits in mouse models of Alzheimer's disease (Shirey et al., 2009) but the mechanism of this reversal is not known. Our data suggest that the enhancement of synaptic plasticity by BQCA might provide the mechanism of enhanced learning. It would be interesting in the future to determine whether synaptic plasticity in mPFC is affected in Alzheimer's disease and whether any plasticity deficits can be reversed by $\mathrm{M}_{1}$-selective positive allosteric modulators or by acetylcholinesterase inhibitors.

\section{References}

Aigner TG, Mitchell SJ, Aggleton JP, DeLong MR, Struble RG, Price DL, Wenk GL, Pettigrew KD, Mishkin M (1991) Transient impairment of recognition memory following ibotenic-acid lesions of the basal forebrain in macaques. Exp Brain Res 86:18-26.

Anagnostaras SG, Murphy GG, Hamilton SE, Mitchell SL, Rahnama NP, Nathanson NM, Silva AJ (2003) Selective cognitive dysfunction in acetylcholine $M_{1}$ muscarinic receptor mutant mice. Nat Neurosci 6:51-58.

Auerbach JM, Segal M (1994) A novel cholinergic induction of long-term potentiation in rat hippocampus. J Neurophysiol 72:2034-2040.

Auerbach JM, Segal M (1996) Muscarinic receptors mediating depression and long-term potentiation in rat hippocampus. J Physiol 492:479-493.

Barker GR, Warburton EC (2009) Critical role of the cholinergic system for object-in-place associative recognition memory. Learn Mem 16:8-11.

Barker GR, Bird F, Alexander V, Warburton EC (2007) Recognition memory for objects, place, and temporal order: A disconnection analysis of the role of the medial prefrontal cortex and perirhinal cortex. J Neurosci 27:2948-2957.

Bartlett TE, Bannister NJ, Collett VJ, Dargan SL, Massey PV, Bortolotto ZA, Fitzjohn SM, Bashir ZI, Collingridge GL, Lodge D (2007) Differential roles of NR2A and NR2B-containing NMDA receptors in LTP and LTD in the CA1 region of two-week old rat hippocampus. Neuropharmacology 52:60-70.

Bear MF, Abraham WC (1996) Long-term depression in hippocampus. Annu Rev Neurosci 19:437-462.

Bilkey DK (1996) Long-term potentiation in the in vitro perirhinal cortex displays associative properties. Brain Res 733:297-300.

Bliss TV, Collingridge GL (1993) A synaptic model of memory: Long-term potentiation in the hippocampus. Nature 361:31-39.

Blitzer RD, Gil O, Landau EM (1990) Cholinergic stimulation enhances long-term potentiation in the CA1 region of rat hippocampus. Neurosci Lett 119:207-210.

Bonsi P, Martella G, Cuomo D, Platania P, Sciamanna G, Bernardi G, Wess J, Pisani A (2008) Loss of muscarinic autoreceptor function impairs longterm depression but not long-term potentiation in the striatum. J Neurosci 28:6258-6263.

Bröcher S, Artola A, Singer W (1992) Agonists of cholinergic and noradrenergic receptors facilitate synergistically the induction of long-term potentiation in slices of rat visual cortex. Brain Res 573:27-36.

Broersen LM, Heinsbroek RP, de Bruin JP, Uylings HB, Olivier B (1995) The role of the medial prefrontal cortex of rats in short-term memory functioning: Further support for involvement of cholinergic, rather than dopaminergic mechanisms. Brain Res 674:221-229.

Browning PG, Easton A, Buckley MJ, Gaffan D (2005) The role of prefrontal cortex in object-in-place learning in monkeys. Eur J Neurosci 22:3281-3291.

Buchanan KA, Petrovic MM, Chamberlain SE, Marrion NV, Mellor JR (2010) Facilitation of long-term potentiation by muscarinic M(1) receptors is mediated by inhibition of SK channels. Neuron 68:948-963.

Burgard EC, Sarvey JM (1990) Muscarinic receptor activation facilitates the induction of long-term potentiation (LTP) in the rat dentate gyrus. Neurosci Lett 116:34-39.

Caruana DA, Chapman CA (2008) Dopaminergic suppression of synaptic transmission in the lateral entorhinal cortex. Neural Plast 2008:203514.

Caruana DA, Reed SJ, Sliz DJ, Chapman CA (2007) Inhibiting dopamine reuptake blocks the induction of long-term potentiation and depression in the lateral entorhinal cortex of awake rats. Neurosci Lett 426:6-11.

Cho K, Kemp N, Noel J, Aggleton JP, Brown MW, Bashir ZI (2000) A new form of long-term depression in the perirhinal cortex. Nat Neurosci 3:150-156.

Dalley JW, Cardinal RN, Robbins TW (2004) Prefrontal executive and cognitive functions in rodents: Neural and neurochemical substrates. Neurosci Biobehav Rev 28:771-784. 
Delatour B, Witter MP (2002) Projections from the parahippocampal region to the prefrontal cortex in the rat: evidence of multiple pathways. Eur J Neurosci 15:1400-1407.

Dunnett SB, Wareham AT, Torres EM (1990) Cholinergic blockade in prefrontal cortex and hippocampus disrupts short-term memory in rats. Neuroreport 1:61-64.

Ebert U, Kirch W (1998) Scopolamine model of dementia: electroencephalogram findings and cognitive performance. Eur J Clin Invest 28:944-949.

Eglen RM (2006) Muscarinic receptor subtypes in neuronal and nonneuronal cholinergic function. Auton Autacoid Pharmacol 26:219-233.

Everitt BJ, Robbins TW (1997) Central cholinergic systems and cognition. Annu Rev Psychol 48:649-684.

Garden DL, Massey PV, Caruana DA, Johnson B, Warburton EC, Aggleton JP, Bashir ZI (2009) Anterior thalamic lesions stop synaptic plasticity in retrosplenial cortex slices: expanding the pathology of diencephalic amnesia. Brain 132:1847-1857.

Griffiths S, Scott H, Glover C, Bienemann A, Ghorbel MT, Uney J, Brown MW, Warburton EC, Bashir ZI (2008) Expression of long-term depression underlies visual recognition memory. Neuron 58:186-194.

Harvey J, Balasubramaniam R, Collingridge GL (1993) Carbachol can potentiate $\mathrm{N}$-methyl-D-aspartate responses in the rat hippocampus by a staurosporine and thapsigargin-insensitive mechanism. Neurosci Lett 162:165-168.

Hess G, Donoghue JP (1999) Facilitation of long-term potentiation in layer II/III horizontal connections of rat motor cortex following layer I stimulation: route of effect and cholinergic contributions. Exp Brain Res 127:279-290.

Hirotsu I, Hori N, Katsuda N, Ishihara T (1989) Effect of anticholinergic drug on long-term potentiation in rat hippocampal slices. Brain Res 482:194-197.

Hoover WB, Vertes RP (2007) Anatomical analysis of afferent projections to the medial prefrontal cortex in the rat. Brain Struct Funct 212:149-179.

Huang CC, Hsu KS (2010) Activation of muscarinic acetylcholine receptors induces a nitric oxide-dependent long-term depression in rat medial prefrontal cortex. Cereb Cortex 20:982-996.

Huber KM, Roder JC, Bear MF (2001) Chemical induction of mGluR5- and protein synthesis-dependent long-term depression in hippocampal area CA1. J Neurophysiol 86:321-325.

Ito T, Miura Y, Kadokawa T (1988) Physostigmine induces in rats a phenomenon resembling long-term potentiation. Eur J Pharmacol 156:351-359.

Jay TM, Witter MP (1991) Distribution of hippocampal CA1 and subicular efferents in the prefrontal cortex of the rat studied by means of anterograde transport of Phaseolus vulgaris-leucoagglutinin. J Comp Neurol 313:574-586.

Jo J, Son GH, Winters BL, Kim MJ, Whitcomb DJ, Dickinson BA, Lee YB, Futai K, Amici M, Sheng M, Collingridge GL, Cho K (2010) Muscarinic receptors induce LTD of NMDAR EPSCs via a mechanism involving hippocalcin, AP2 and PSD-95. Nat Neurosci 13:1216-1224.

Katsuki H, Saito H, Satoh M (1992) The involvement of muscarinic, betaadrenergic and metabotropic glutamate receptors in long-term potentiation in the fimbria-CA3 pathway of the hippocampus. Neurosci Lett 142:249-252.

Kemp N, Bashir ZI (2001) Long-term depression: a cascade of induction and expression mechanisms. Prog Neurobiol 65:339-365.

Kesner RP, Ragozzino ME (2003) The role of the prefrontal cortex in objectplace learning: a test of the attribute specificity model. Behav Brain Res 146:159-165.

Kirkwood A, Rozas C, Kirkwood J, Perez F, Bear MF (1999) Modulation of long-term synaptic depression in visual cortex by acetylcholine and norepinephrine. J Neurosci 19:1599-1609.

Kobayashi M, Ohno M, Shibata S, Yamamoto T, Watanabe S (1997) Concurrent blockade of beta-adrenergic and muscarinic receptors suppresses synergistically long-term potentiation of population spikes in the rat hippocampal CA1 region. Brain Res 777:242-246.
Kojima J, Onodera K (1998) NIK-247 induces long-term potentiation of synaptic transmission in the CA1 region of rat hippocampal slices through M2 muscarinic receptors. Gen Pharmacol 31:297-300.

Levey AI (1996) Muscarinic acetylcholine receptor expression in memory circuits: Implications for treatment of Alzheimer disease. Proc Natl Acad Sci U S A 93:13541-13546.

Ma L, Seager MA, Wittmann M, Jacobson M, Bickel D, Burno M, Jones K, Graufelds VK, Xu G, Pearson M, McCampbell A, Gaspar R, Shughrue P, Danziger A, Regan C, Flick R, Pascarella D, Garson S, Doran S, Kreatsoulas C, et al. (2009) Selective activation of the $M_{1}$ muscarinic acetylcholine receptor achieved by allosteric potentiation. Proc Natl Acad Sci U S A 106:15950-15955.

Markram H, Segal M (1990) Acetylcholine potentiates responses to $N$-methyl-D-aspartate in the rat hippocampus. Neurosci Lett 113:62-65.

Massey PV, Bhabra G, Cho K, Brown MW, Bashir ZI (2001) Activation of muscarinic receptors induces protein synthesis-dependent long-lasting depression in the perirhinal cortex. Eur J Neurosci 14:145-152.

McCaffery B, Cho K, Bortolotto ZA, Aggleton JP, Brown MW, Conquet F, Collingridge GL, Bashir ZI (1999) Synaptic depression induced by pharmacological activation of metabotropic glutamate receptors in the perirhinal cortex in vitro. Neuroscience 93:977-984.

McCoy PA, McMahon LL (2007) Muscarinic receptor dependent longterm depression in rat visual cortex is PKC independent but requires ERK1/2 activation and protein synthesis. J Neurophysiol 98:1862-1870.

Mrzljak L, Pappy M, Leranth C, Goldman-Rakic PS (1995) Cholinergic synaptic circuitry in the macaque prefrontal cortex. J Comp Neurol 357:603-617.

Patil MM, Linster C, Lubenov E, Hasselmo ME (1998) Cholinergic agonist carbachol enables associative long-term potentiation in piriform cortex slices. J Neurophysiol 80:2467-2474.

Paxinos G, Watson C (1998) The rat brain in stereotaxic coordinates. New York: Academic.

Ragozzino ME, Kesner RP (1998) The effects of muscarinic cholinergic receptor blockade in the rat anterior cingulate and Prelimbic/Infralimbic cortices on spatial working memory. Neurobiol Learn Mem 69:241-257.

Ross RS, McGaughy J, Eichenbaum H (2005) Acetylcholine in the orbitofrontal cortex is necessary for the acquisition of a socially transmitted food preference. Learn Mem 12:302-306.

Sheffler DJ, Williams R, Bridges TM, Xiang Z, Kane AS, Byun NE, Jadhav S, Mock MM, Zheng F, Lewis LM, Jones CK, Niswender CM, Weaver CD, Lindsley CW, Conn PJ (2009) A novel selective muscarinic acetylcholine receptor subtype 1 antagonist reduces seizures without impairing hippocampus-dependent learning. Mol Pharmacol 76:356-368.

Shirey JK, Brady AE, Jones PJ, Davis AA, Bridges TM, Kennedy JP, Jadhav SB, Menon UN, Xiang Z, Watson ML, Christian EP, Doherty JJ, Quirk MC, Snyder DH, Lah JJ, Levey AI, Nicolle MM, Lindsley CW, Conn PJ (2009) A selective allosteric potentiator of the $\mathrm{M}_{1}$ muscarinic acetylcholine receptor increases activity of medial prefrontal cortical neurons and restores impairments in reversal learning. J Neurosci 29:14271-14286.

Volk LJ, Pfeiffer BE, Gibson JR, Huber KM (2007) Multiple Gq-coupled receptors converge on a common protein synthesis-dependent long-term depression that is affected in fragile $\mathrm{X}$ syndrome mental retardation. J Neurosci 27:11624-11634.

Wang L, Yuan LL (2009) Activation of M2 muscarinic receptors leads to sustained suppression of hippocampal transmission in the medial prefrontal cortex. J Physiol 587:5139-5147.

Warburton EC, Koder T, Cho K, Massey PV, Duguid G, Barker GR, Aggleton JP, Bashir ZI, Brown MW (2003) Cholinergic neurotransmission is essential for perirhinal cortical plasticity and recognition memory. Neuron 38:987-996.

Ziakopoulos Z, Tillett CW, Brown MW, Bashir ZI (1999) Input-and layerdependent synaptic plasticity in the rat perirhinal cortex in vitro. Neuroscience 92:459-472. 